DOE/PC/30198-T2

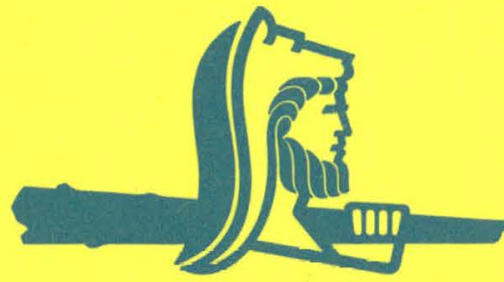

HERCULES

I NCORPORATED

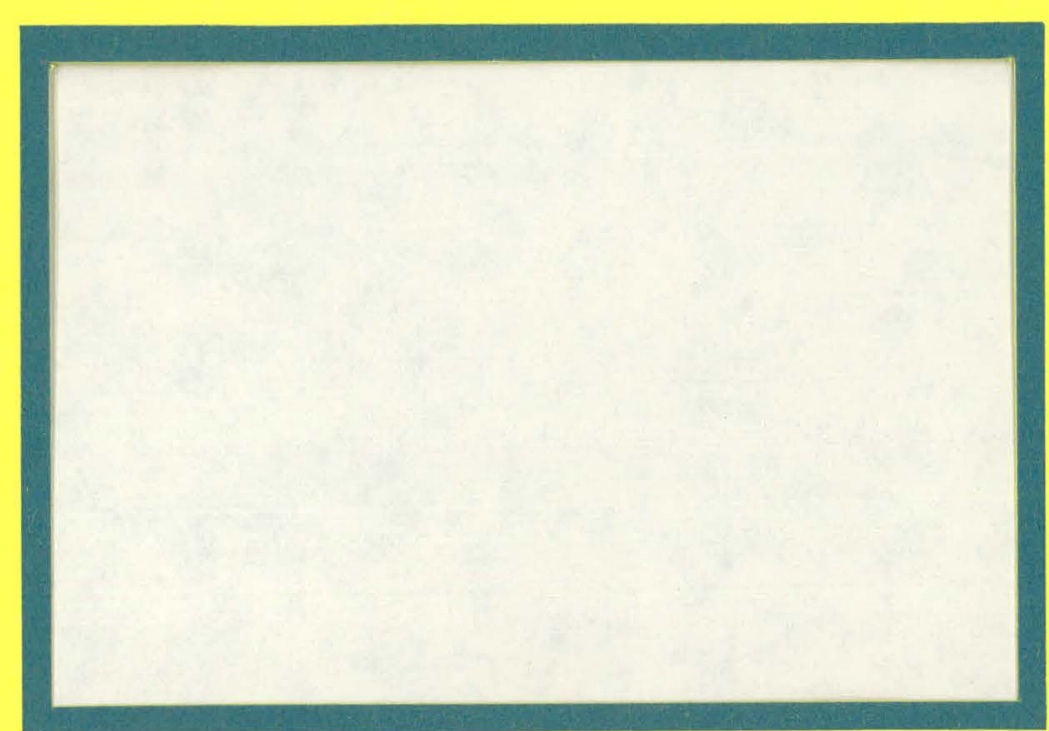

\title{
HAZARD ANALYSIS REPORT
}

\section{HERC}




\section{DISCLAIMER}

This report was prepared as an account of work sponsored by an agency of the United States Government. Neither the United States Government nor any agency Thereof, nor any of their employees, makes any warranty, express or implied, or assumes any legal liability or responsibility for the accuracy, completeness, or usefulness of any information, apparatus, product, or process disclosed, or represents that its use would not infringe privately owned rights. Reference herein to any specific commercial product, process, or service by trade name, trademark, manufacturer, or otherwise does not necessarily constitute or imply its endorsement, recommendation, or favoring by the United States Government or any agency thereof. The views and opinions of authors expressed herein do not necessarily state or reflect those of the United States Government or any agency thereof. 


\section{DISCLAIMER}

Portions of this document may be illegible in electronic image products. Images are produced from the best available original document. 


\section{HERCULES AEROSPACE DIVISION HERCULES INCORPORATED ALLEGANY BALLISTICS LABORATORY CUMBERLAND, MARYLAND}

\section{MIANAGEMENT IMPLEMENTATION PLAN FOR A SAFETY ANALYSIS AND REVIEW SYSTEM}

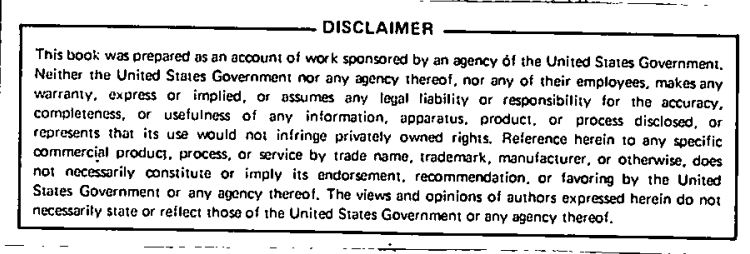

APRIL 1981

D. A. HULBURT

B. D. BERKEY

PREPARED FOR

U. S. DEPARTMENT OF ENERGY

PITTSBURGH EN.ERGY.T'ECHNOLOGY CENTER

PITTSBURGH; PENNSYLVANIA

Contract DE-AC22-80PC 30198

Task 4

Report No. A08639-520-03-009

HERC NO. $81-19$ 
THIS PAGE

\section{WAS INTENTIONALLY LEFT BLANK}


TABLE OF CONTENTS

\section{Page}

List of Tables

iv

List of Figures

Abbreviations

vi

Definitions

vii

I. INTRODUCTION AND SUMMARY

1
A. Purpose and Scope
B. Overview
C. Guiding Principles"s

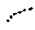

1

- . 12

II. ADMINISTRATIVE PROCEDURES

A. Determination of Safety Analysis Requirements 7

B. Providing the Safety Analysis 12 -

C. Review of the Safety Analysis and Authorization of the 15 Operation

D. Modifications to the Operation 18

E. Backfitting $\quad 22$

III. SAFETY ANALYSIS TECHNICAL SPECIFICATIONS $\quad 23$

A. Safety Analysis Requirement Determination 23

B. Safety Analysis Data Package 33

C. Safety Analysis Requirements $\quad 38$

D. Process Hazards Änalysis Requirements

E. Workplace Health Analysis Requirements ‥ . . 53

F. Workplace Safety Analysis Requirements $\quad 56$

G. Environmental Analysis Requirements 59

BIBLIOGRAPHY $\cdot \because \cdot \quad \cdot \quad 62$

Appendixes

A. Operational Hazards 64

B. Level of Analysis 65

C. Timing of a SAR 66

D. Budgetary Cost Estimates . : 67

E. Hazard Severity Categories . . . . 68

F. Recommendation Guidelines. 69 


\section{LIST OF TABLES}

Table No.

Title

$\underline{\text { Page }}$

I - Guidelines for Assigning Modification Levels

$20 \quad$ is

II - Dperation Characteristics Definitions

III - Examples of Major Équipment

IV - Hazard Severity Catagories

39

V - Composition of the Safety Analysis

41

VI - Recommendation Guidelines

VII - Typical Workplace Safety Hazards 


\section{LIST OF FIGURES}

Figure No.

Title

Page

1 Safety Analysis and Review and the Project Life Cycle

2 Safety Analysis Requirement Determination

8

3 Safety Analysị Requirement Determination - Backfit

9

4 Safety Analysis Review and Authorization of the $\quad \therefore 16$ Operation

5 Modiflcations to the Operation

6 SA Requirement Determination Logic Diagram

7 Qualitative Process Hazards Analysis Sheet - Illustrative Example

8 Hazards Analysis Identification/qualification Fact Sheet - Example

9 Hazards Analysis Consequence/Severity Analysis Example 
$\mathrm{AD}$

ASME

BC

CAM

DEMO

DM

DOE

EIS

ES\&H

FE

FMEA

FTA

NFPA

PDU

PETC

PM

PTD

R\&D

RFP

SA

SAR
Assistant Director

American Society of Mechanical Engineers

Branch Chief

Cost Account Manager

Demonstration Unit

Division Manager

Department of Energy

Environmental Impact Statement

Environment, Safety and Health

Fossil Energy

Failure Modes and Effects Analysis

Fault Tree Analysis

National Fire Protection Association

Process Development Unit

Pittsburgh Energy Technology Center

Project Manager

Permanent Total Disability

Research and Development

Request for Proposal

Safety Analysis.

Safety Analysis and Review 
Authorization - Authorization as used herein means authorization of the Operation in written form, and designates that the Risks of the Operation are acceptable to DOE/PETC.

DOE Operation - A DOE-funded facility, activity, or project for which DOE has assumed programmatic responsibility for health, safety or environmental protection, and which presents hazards of a type or magnitude that are not routinely encountered and/or accepted by the public. It is a general term intended to encompass individual operations or efforts in the aggregate rather than separately.

Environmental Analysis - A systematic evaluation of an Operation which addresses hazards to the environment due to emissions, effluents, or waste disposal under normal operational conditions. The evaluation includes identification of environmental hazards, assessment of likelihood and consequences, and recommendations for preventive or mitigative control measures.

Process Hazards Analysis - A systematic evaluation of an Operation which addresses hazards due to component failure(s); operator error(s), procedural deficiency(ies), design characteristics, or combinations thereof. The analysis identifies fire/explosion, pressurization failure, and material release hazards. Evaluation includes assessment of likelihood of occurrence and consequences to people, property, and the environment. Recommendations for elimination, mitigation, or control of potential hazards are included.

Safety Analysis - A systematic evaluation of an Operation consisting of a Process Hazards Analysis, a Workplace Health Analysis, a Workplace Safety Analysis, and an Environmental Analysis, and in accordance with the requirements of DOE Order 5481.1.

Safety Analysis Requirement Determination - An evaluation of an Operation to determine if the Operation is 1) excluded from DOE 5481.1 for administrative reasons, 2) excluded from DOE 5481.1 for technical reasons, or 3) requires an SA under DOE 5481.1, to determine the level of SA appropriate if one is required, and establish a budget allocation for the SA.

Titles - All titles such as Director, Assistant Director, Division Manager, etc. refer to offices of the Pittsburgh Energy Technology Center unless otherwise specified.

Workplace Health Analysis - A systematic evaluation of an Operation to Identify occupational health hazards due to exposüre under normal operational conditions. Consequences of exposure are evaluated and recommendations made to eliminate, mitigate, or control the potential health hazard. 
Workplace Safety Analysis - A systematic evaluation of an Operation to identify occupational injury hazards under normal operational conditions and recommend measures to eliminate, mitigate, or control the hazards. 


\section{SECTION I}

\section{INTRODUCTION AND SUMMARY}

\section{A. PURPOSE AND SCOPE}

The U. S. Department of Energy has issued an Order, DOE 5481.1, which establishes uniform requirements for the preparation and review of Safety Analys1s for DOE Operations... The Management Implementation Plan specified herein establishes the administrative procedures and technical requirements for implementing DOE 5481.1 to Operations under the cognizance of the Pittsburgh Energy Technology Center.

This Implementation Plan is applicable to all present and future Operations under the cognizance of PETC. The Plan identifies those Operations for which DOE 5481.1 is applicable and those Operations for which no further analysis is required because the initial determination and review has concluded that DOE 5481.1 does not apply.

The objectives of the Implementation Plan are to assure that the objectives of DOE 5481.1 are fulfilled in a uniform, consistent, and complete manner at a level of effort appropriate to the potential risks of the Operation involved. These objectives are:

1. Potential hazards are systematically identified.

2. Potential impacts of hazards are analyzed.

3. Reasonable measures to eliminate, control, or mitigate unacceptable hazards have been taken.

4. There is documented management authorization of Operations based on an objective review of the Safety Analysis.

\section{B. OVERVIEW}

The Implementation Plan has been developed to be compatible with the existing management system for planning and executing projects/tasks (PETC Annual Control Process Program). Safety Analysis and Review requirements are determined at the earliest phase in the project life cycle, and the iife cycle of the SAR is established to parallel and complement the project life cycle. This assures that early hazard identification and elimination/control is facilitated and that SAR requirements are fulfilled consistent with the other life cycle milestones of the Operation.

Administrative procedures are established to specify the mechanisms for accomplishing the following: 
1. Determination of $\mathrm{SA}$ requirements

2. Providing the SA.

3. Review of the SA and Authorization of the Operation.

4. Modifications to the Operation.

5. Backfitting

Technical specifications are established to specify the requirements for the following:

1. Determining if an Operation requires a SAR.

2. Determining the appropriate level of $\mathrm{SA}$, if one is required.

3. Specifying the content for each of three levels of SA.

The SA is defined to consist of four constituent analyses: Process Hazards Analysis, Workplace Health Analysis, Workplace Safety Analysis, and Environmental Analysis. Specifications and requirements are provided for each of these four constituent analyses.

A simplified block diagram showing the SAR life cycle and its relation to the project Iffe cycle and PETC Annual Control Process Program is presented in Figure 1.

\section{GUIDING PRINCIPLES}

The Implementation Plan was developed in accordance with a set of guiding principles, or philosophy of safety. For the most part, these principles are also requirements of DOE Order 5481.1, and are so identified as they are discussed. In some instances, the principles are not spectfically required by DOE 5481.1, but are judged to be valid and sound principles for any safety program and were therefore incorporated in the Implementation Plan. These are also identified as such. The guiding principles are enumerated below and discussed individually in subsequent paragraphs.

1. Safety is a Line Program Responsibility.

2. ES\&H is a S.taff Function.

3. Independent Preparation of the SA.

4. Independent Review of the SA.

5. Action at the Lowest Level Cọmensurate With the Risk. 


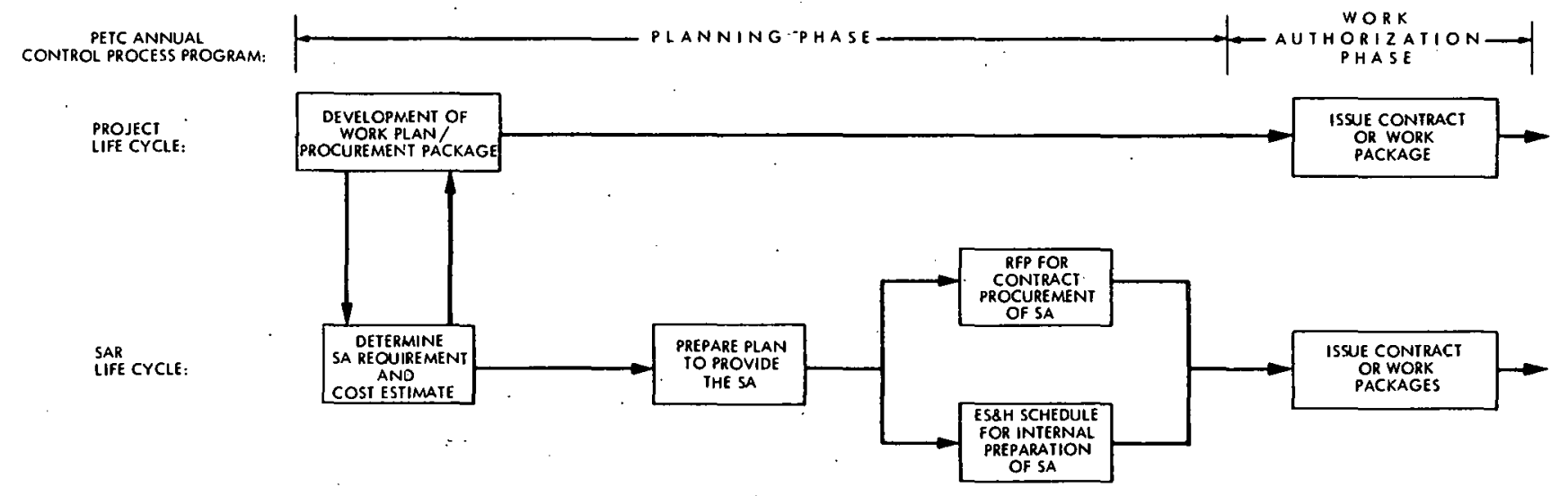

$\omega$
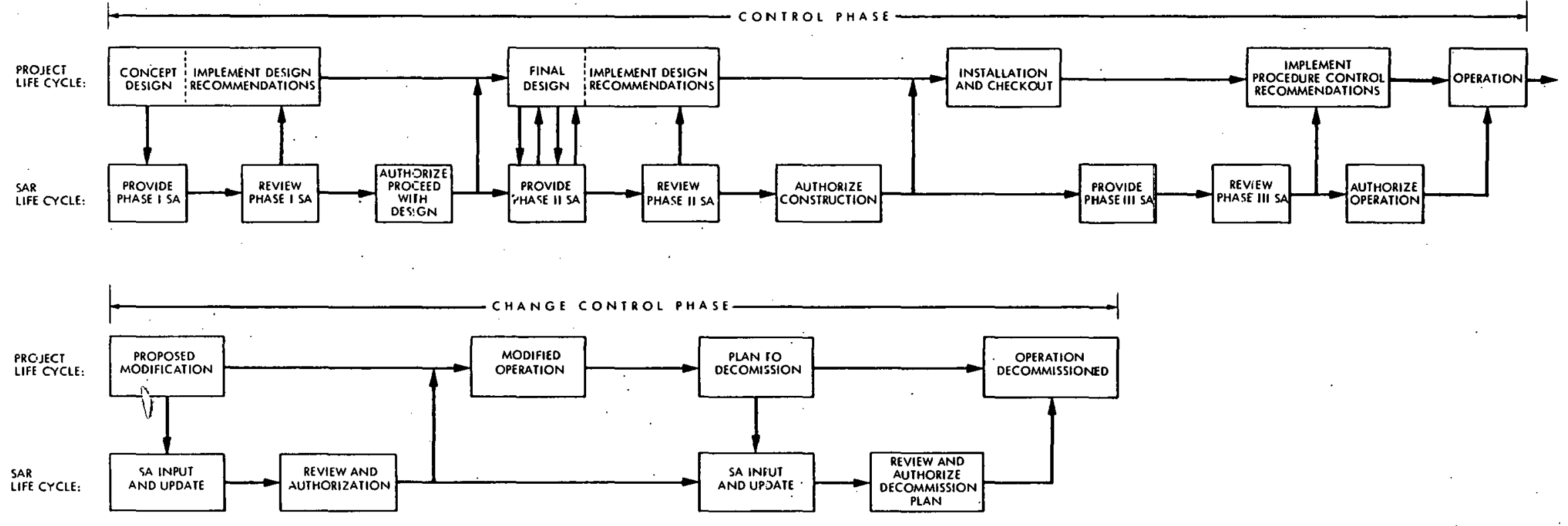

Figure 1. Safety Analysis and Review and the Project Life Cycle 
6. Safety Involvement Throughout the Life Cycle.

7. Graduated Levels of SA Commensurate With Risk.

8. SAR Implementation Plan Fits Existing Administrative Systems

\section{Safety is a Line Program Responsibility}

DOE Order 5481.1 clearly establishes that the Line Program Organization responsible for an Operation has basic responsibility for the health, safety, and environmental protection of that Operation, and therefore basic responsibility for implementing the Safety Analysis and Review System Requirements. This policy conforms to the generally held philosophy that safety is a line function and therefore a basic responsibility of line management. Accordingly, the Implementation Plan assigns basic responsibilities for safety analysis and decision-making to the Line Program Organization.

\section{ES\&H is a Staff Function}

The ES\&H Division is considered to be a staff organization which exists to provide the Line Organization with technical information and specialized expertise or advise on ES\&H matters to aid the Line Program Management in fulfilling its responsibilities and enabling it to reach decisions on an informed basis. Accordingly, the Implementation Plan assigns the ES\&H Division roles of advisor, reviewer, and/or approver of the adequacy of safety studies and assessments. Thus the PETC ES\&H organization is viewed as fulfilling a function similar to the Headquarters EV organization in the context of DOE 5481.1.

\section{Independent Preparation of the SA}

DOE Order 5481.1 requires that the Safety Analysis; when required, be provided by the organization with immediate operating responsibility, in accordance with the principle of Line Program Responsibility. While this responsibility is specifically assigned, it is also recognized that it is good practice for the actual analysis to be performed by an individual or individuals who can view the Operation solely from a safety point of view. This avoids possible problems of 'perception set', and insures an evaluation which is independent of the design or operating function. Accordingly, the Implementation Plan specifies that SAR preparation should be done by personnel not directly. involved in the management of the Operation. Practically, this means that a SAR should be done by ES\&H personnel, by specially trained technical personnel not directly involved in the Operation, or by technical support contractors.

\section{Independent Review of the SA}

DOE 5481.1 requires that the Safety Analysis be reviewed by individuals, the majority of whom are not directly involved in the management 
of the Operation being evaluated. This policy is consistent with the principle of insuring that an independent review be made, and acts to prevent possible subjugation of ES\&H concerns to other programmatic considerations. Accordingly, the Implementation Plan specifies Review by either the ES\&H Division, or by the PETC Safety Analysis. Review Committee, depending on the size of the Operation and magnitude of potential risks involved.

\section{5.. Action at Lowest Leve1 Commensurate With Risk}

The Implementation Plan has been developed with the principle of 'action at the lowest organizational leve1.' commensurate with the risks involved. This principle is judged as valid and good practice for several. reasons. First, it keeps safety responsibilities close to the Operation, which serves to further safety awareness and committment in those directly involved. Experience has shown that the immediate operating supervisor is the key man in any Safety effort. Second, it avoids involving all of management, with consequent scheduling and timing problems, in matters which represent a low level concern. At the same time, however, it requires upper management involvement and authorization in matters which represent potential high risk concems. This principle applies to determination of SA requirements, authorization of operations, and assessment and authorization of modifications to operations.

\section{6: Safety Involvement Throughout the Tife Cycle}

DOE 5481.1 requires that safety analysis shall be initiated during the earliest phases of the life cycle of the Operation, to facilitate early hazard identification and their elimination or control. Early identification of safety analysis requirements is also necessary in order to develop budgetary requirements, funding, and implementation plans. This will insure that Safety Analysis and Review requirements are compatible with the overall project schedule. Accordingly, the Implementation Plan requires. SAR activities concurrent with the earliest and subsequent planning phases of a project. Experience has shown that a three-phase SA approach, corresponding to concept design, final design, and installation phases of the Operation, is generally the most cost-effective. During the Operational phase, the SA must be kept current with operational changes to prevent introduction of hazards via the changes. Review of all proposed modifications is required.

\section{Graduated Levels of SA, Commensurate With Risk}

It is recognized that the variety of Operations for which PETC may have cognizance will cut across a broad spectrum in terms of types or potential magnitudes of risk. In order to tailor the analysis to each type of risk, and provide some flexibility with regard to magnitude of risk, the Implementation Plan is based on partitioning a Safety Analysis into four constituent analyses: 1) Process Hazards Analysis, 2) Workplace Health Analysis, 3) Workplace Safety Analysis, and 4) Environmental Analysis. Process Hazards Analysis represents the 'heart' of the Safety Analysis effort 
and is also the most variable in terms of effort as a function of the type and/or size of Operation involved. Accordingly, three levels of Process Hazards Arialysis are developed to provide appropriate levels of effort commensurate with the risks involved in the Operation.

\section{SAR Implementation PIan Fits Existing Administrative Systems}

It is also recognized that the development of a totally independent system for administering the Safety Analysis and Review System would represent a duplication of some existing systems and might therefore be unmanageable. Accordingly, the Implementation Plan has been integrated with the PETC Annual Control Process Program for the planning and administration of projects/tasks. The Plan therefore is compatible with the existing management system at PETC. 


\title{
ADMINISTRATIVE PROCEDURES
}

\begin{abstract}
This section establishes the administrative requirements and mechanisms to implement the Safety Analysis and Review (SAR) System for Operations under the cognizance of PETC, as required by DOE Order 5481.1. The admintstrative procedures established herein are applicable to all Operations under the cognizance of PETC. Backfit SA is 'triggered' by the "Work Plan" or"Procurement Package" for operating an on-going operation or renewal/extension of an existing contract. The administrative procedures are presented in five subsections: A - Determination of Safety Analysis Requirements, B - Providing the Safety Analysis, C-Review of the Safety Analysis and Authorization of the Operation, D - Modifications to the Operation, and $E$ - Backfitting.
\end{abstract}

\section{A. DETERMINATION OF SAFETY ANALYSIS REQUIREMENTS}

Safety Analysis requirements must be determined in the earliest phases of the life cycle of the Operation in order that early hazard identification and elimination/control may be facilitated and that budgetary requirements for the Safety Analysis and Review function may be established. This will insure timely completion of Safety Analysis and Review requirements consiscent with the other life cycle milestones of the Operation. The preparation of the Work Plan/Procurement Package for the Operation normally represents the earliest phase in the life cycle for which sufficlent technical detail to determine SA requirements is known. If sufficient information about the Operation is known prior to this, the determination may be made earlier. If significant changes to the Work Plan/Procurement Package are made subsequent to determining the SA requirements, a revised SA Requirement Determination should be made.

Safety Analysis requirements are determined by performing a SA Requirement Determination, which consists of a package of Checksheets, as specified in Section III, Subsection A.

1. Determination of $S A$ requirements shall be made in conjunction with the preparation of the Work Plan/Procurement Package for the proposed Operation. The purposes of the determination are to 1 ) establish whether or not the Operation requires a SA, and 2) establish a budgetary estimate of the effort needed to fulfill SA requirements.

2. The determination shall be performed by the $B C / C A M$ or $\mathrm{DM} / \mathrm{PM}$, in accordance with the procedure described in the decision diagram in Figure 2. Backfit Operations also require use of Figure 3. 


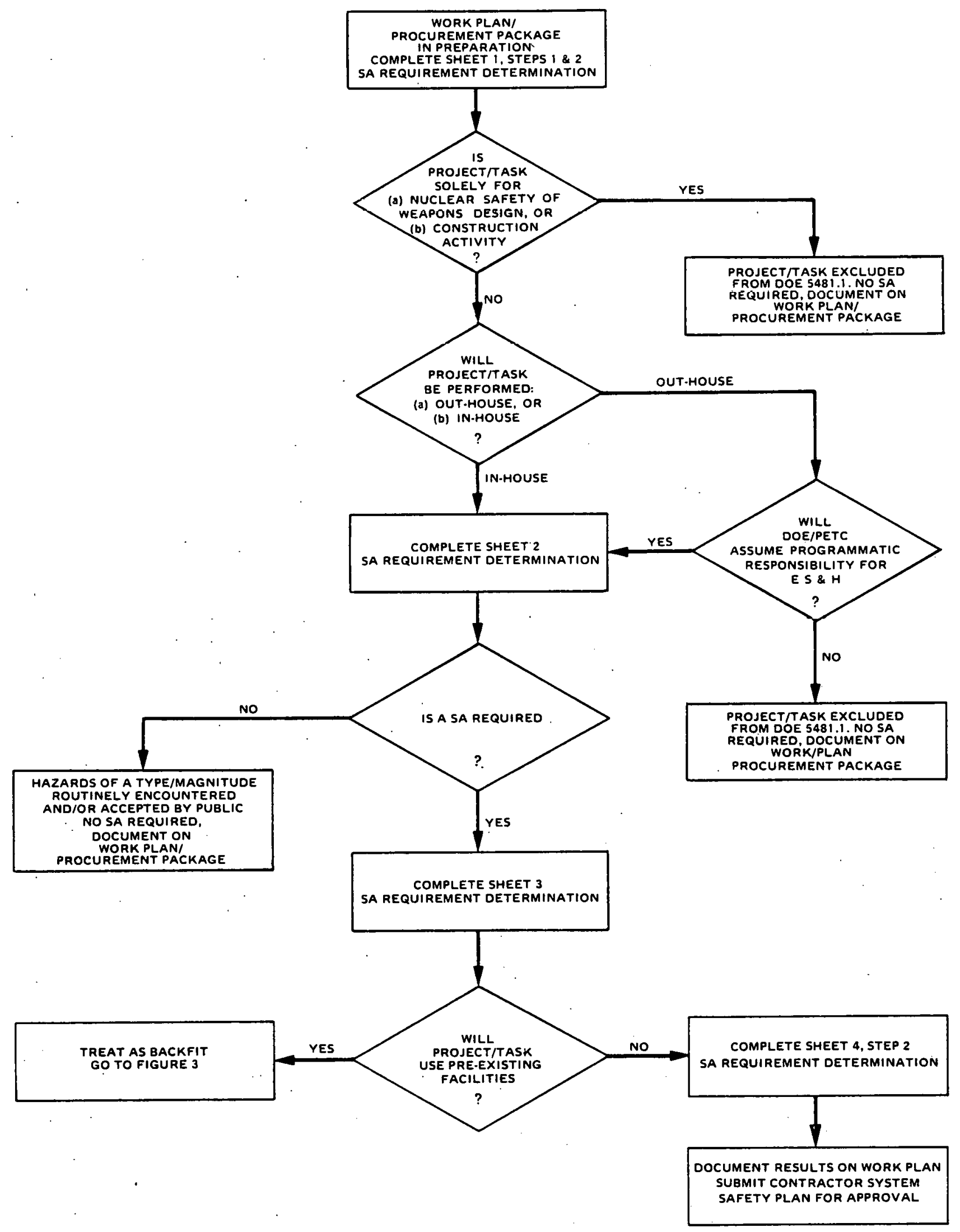

Figure 2. SA Requirement Determination 


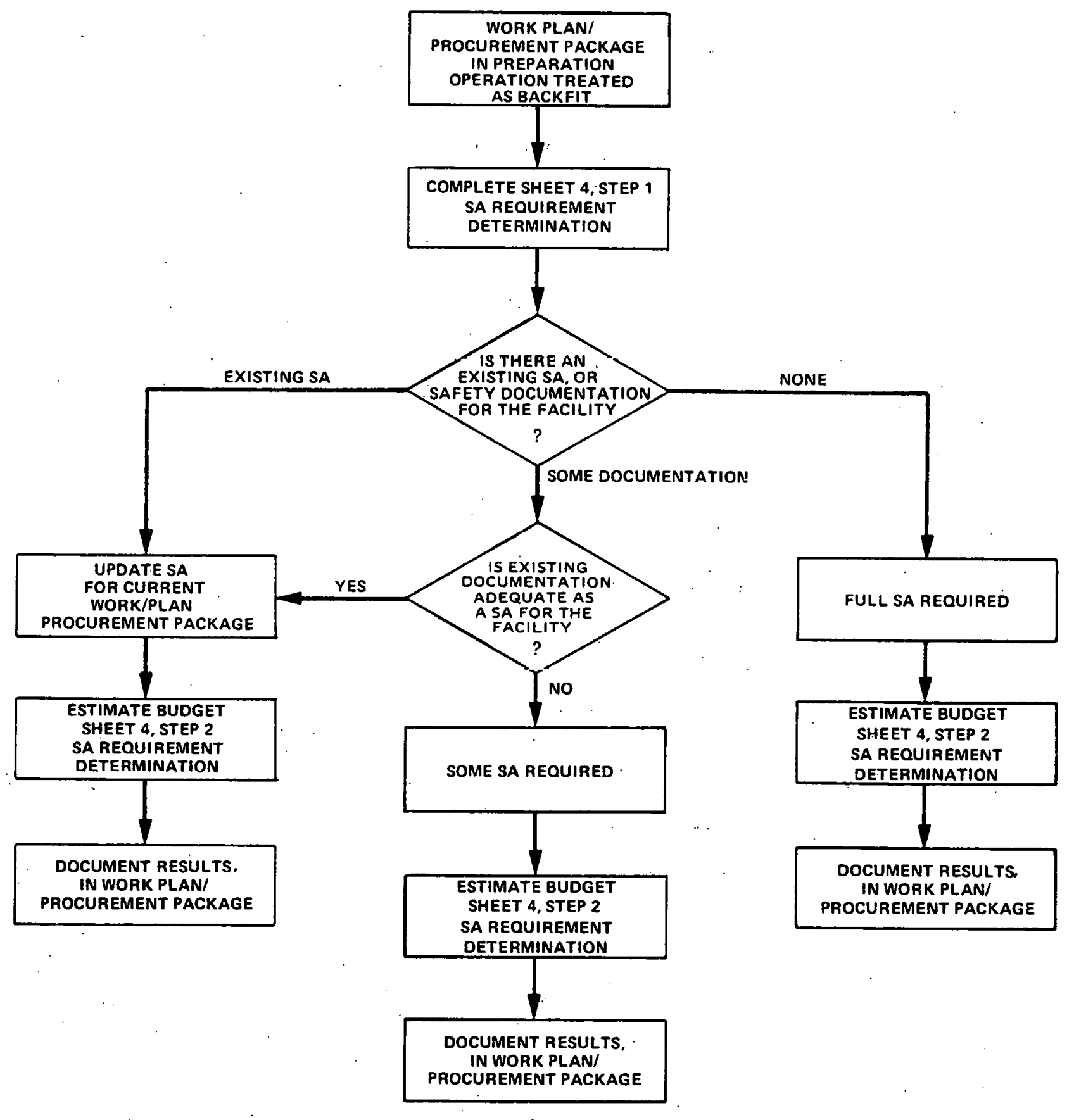

Figure 3. SA Requirement Determination-Backfit Adaptation 
3. SA requirements shall be documented on the Work Plan/ Procurement Package (contractual clauses/statement of work).

a. If the determination indicates the proposed Operation is excluded from DOE 5481.1 because it is: 1) solely a construction related activity, or 2) nuclear safety of weapons designs, a statement to that effect shall be included in the Work P1an/Procurement Package.

b. If the determination indicates no SA is required because the proposed Operation will be an out-house contract for which DOE/PETC does not intend to assume programmatic responsibility for ES\&H, a statement to that effect shall be included in the Procurement Package.

c. If the determination indicates no SA is required because the hazards of the proposed Operation are of a type and magnitude routinely encountered and/or accepted by the public, a statement to that effect shall be included in the Work Plan/Procurement Package.

d. If the determination Indicates a SA is required for an in-house Operation, a SA Implementation Plan shall be attached for internal review.

e. If the determination indicates a SA is required for a contractor Operation, and for which DOE has assumed programmatic responsibility for ES\&H, the DOE 5481.1 requirements shall be fully communicated to the contractor in written and verbal form by the responsible Project Manager.

4. The SA Requirement Determination shall he reviewed.by and concurred-in by the Safety Branch. If the Safety Branch does not concur in the Determination or the level of SA to be required, the Safety Branch shall forward their alternate position to the Deputy Director, who shall have delegated authority to establish which position to include in the Work Plan/Procurement Package. The Director, at his discretion, may reserve this authority for himself, or establish criteria upon which his approval is required.

5. The estimate of the SA cost should consider specific input about the Operation to the extent it is known. Several examples of factors which can influence cost are as follows: 
5. a. Operations which include intricate or complex control systems will require greater SA effort than those which do not.

b. The costs for SA of Operations which will use existing facilities will depend on the extent, if any, of existing safety related analysis and the similarity in use of the facility to previous operating experience or SA basis.

c. Operations which are largely couprised of offthe-shelf standard commercial items in normal applications will require less $S A$ effort than those which are not. 


\section{General Requirements}

a. The responsibility for providing the SA of the Operation lies with the line organization with immediate operating responsibility. While the responsibility for provision lies therein, it is advisable that the SA be prepared by an individual or individuals who can view the Operation from solely a safety point of view; i.e., technical personnel within PETC specifically trained in hazards analysis who are not directly involved in the management of the Operation, or technical support contractors.

b. Safety Analysis requirements shall be determined in accordance with Subsection A - Determination of Safety Analysis Requirements.

c. Safety Analysis shall be provided in accordance with Section III - Safety Analysis Technical Specifications.

d. Safety Analysis may be provided as a complete Safety Analysis Package; or separately as individual analysis components; i.e., Process Hazards Analysis, Workplace Safety Analysis, Workplace Health Analysis, Environmental Analysis, or combinations thereof such that ali packages constitute a complete Safety Analysis

e. Experience has shown that a three-phase SA approach is generally desirable for Operations involving design and installation of facilities or equipment, in order to be compatible with evolution of the Operation and to resolve potential ES\&H concerns before committment to hardware is made. In such cases, a preliminary SA (level 1 as defined in Section III) should be provided at the concept design stage, a SA (at level determined by SA Requirement Determination) should be provided during the final design s.tage, and an updated SA should be provided at the completion of installation and prior to startup.

f. For some Operations, it may be desirable to partition the Operation into several sub-Operations, due to clearly defined differences in the types/magnitude of hazards involved; and provide the SA on a subOperation basis. This may result in reducing the overall SA effort required, by scoping out portions or applying different levels of SA to different 
B. 1. f. sub-Operations. In other situations, it may be desirable to encompass several similar individual projects, activities or operations (e.g., an entire analytical laboratory) and perform the SA for the aggregate, rather than for each individual operation. Guidance of the Safety Branch should be sought if partitioning or aggregating is contemplated.

g. Safety Analysis, or analysis components, may be prepared intemally by PETC, may be contractually procured as a separate contract, or for out-house contract Operations may be included in the contractors' scope of work.

\section{Plan for Provlding the Safety Analysis}

a. The line organization with responsibility for inhouse Operations shall prepare a SA Implementation Plan in conjunction with the development of the Work Plan.

b. The line organization with the responsibility for contractor Operations shall ensure that the contractor submits a SA Implementation PIan which complies with the intent of DOE Order 5481.1

c. The SA Implementation Plan shall contain the following:

(1) Scope of the SA to be provided.

(2) Number of phases by which SA will be provided.

(3) Level(s) of SA to be provided, and budgetary cost estimate(s).

(4) Plan for providing the SA, or each of the four Analyses comprising a SA, as applicable.

(5) Schedule and milestones for the SA effort consistent with the overall project schedule.

(6) Safety Analysis Data Package.

d. The Safety Analysis Data Package is a package of checksheets which documents information on the Operation. If the SA Implementation Plan calls for Contract Procurement of the SA, the SA Data Package should be included in procurement documents as a basis for the 
B. 2. d. contractor or potential bidders to use in developing SA cost. If the SA will be provided internally, the SA Data Package should be provided to the person(s) who will prepare the SA as a basis for developing manpower and schedule for preparing the SA. The SA Data Package is specified in Section III, Subsection B.

e. The SA Implementation Plan shall be reviewed and concurred-in by the ES\&H Division, and then routed with the Work Plan/Contractor ES\&H Plan for approval.

\section{Contract Procurement of the Safety Analysis}

a. The RFP, Bid Package, and/or Contract for the SA or components thereof shall contain provisions which establish the requirements and content of the Analysis consistent with the level of $S A$ required and the specifications in Section III.

b. If the procurement is for the SA or components thereof of an out-house contract Operation, the RFP, Bid Package, and/or Contract for the Operation shall contaln provisions and clauses which establish 1) the party with responsibility for ES\&H, 2) contractor responsibility for providing specified Analysis, or technical data to the party providing the Specified Analysis, and 3) DOE/PETC review and approval authority, as applicable.

\section{Changes to the SA During Preparation}

a. During the conduct of the SA it may become evident that a level of SA other than that being performed is required. In such cases, budget or contract funding implications may be involved; therefore, such changes shall be authorized by the same individual authorizing the original SA. 


\section{Review of the Safety Analysis}

a. The SA of each Operation shall be independently reviewed in accordance with the requirements of DOE Order 5481.1. The Review shall include a documented evaluation of the completeness and adequacy of the $\mathrm{SA}$, and documented evaluation of the adequacy of the preventive or mitigative design features and administrative controls of the Operation.

b. The Review of Operations for which no SA is required consists of obtaining concurrence of the Safety Branch on the SA Requirement Determination. No further review is required.

c. The review procedure for a $\mathrm{SA}^{-}$is illustrated in Figure 4 .

d. The ES\&H Division shall make an initial review of all SA's to determine completeness before submitting the ¿Á to formal review. If the SA was prepared by ES $\bar{d} H$ personnel, indiyidual (s) other than those who prepared it shall make the initial review.

c. The Review of a Level 1. SA shall be performed by the ES\&H Division. The ES\&H Division Manager shall designate a review team with representation consistent with the ES\&H concerns identified in the SA, and consisting of knowledgeable persons not involved in the preparation of the SA.

f. The review of a Level 2 SA or a Level 3 SA shall be conducted by the PETC Safety Analysis Review Committee. The Director shall designate the members and chairman of the committee. Membership should include the $\mathrm{BC} / \mathrm{CAM}$ or DM/PM. with operating responsibility, other technical personnel knowledgeable in the technical aspects of the Operation, but who are not directly involved in the Operation, and representative(s) from the ES\&H Division. The Committee shall contain a majority of persons who are not directly involved in the management of the Operation being reviewed.

g. The Review shall address each recommendation made in the SA, and shall document recommended action for each recommendation as follows:

\section{(1) Concurrence}

(a) Recommendation should be implemented

(b) Alternate recommendation to accomplish same purpose is offered for implementation. 


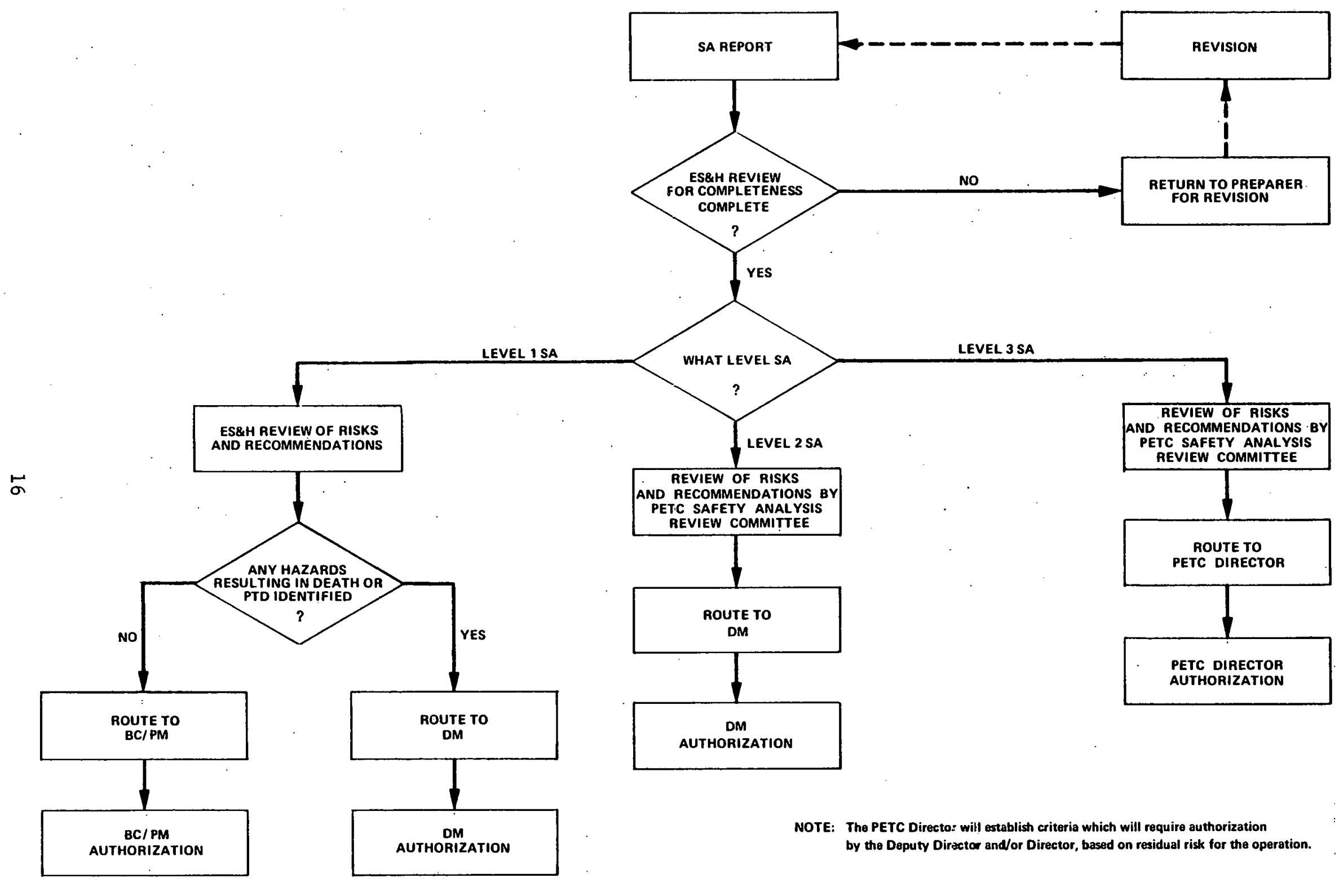

Figure 4. SA Review and Authorization of the Operation 
(2) Non-Concurrence - Recommendation should not be implemented. Basis and reasons for nonconcurrence shall be documented.

h. The Reviewer(s) may offer additional recommendations for implementation not contained in the SA. Alternate means for accomplishing the same objective of preventing, mitigating, or controlling hazards may be proposed, with the recommendation that the optimum alternate based on a cost-benefit study be implemented.

i. PETC may elect to employ outside technical support contractors and/or consultants in conjunction with, or in lieu of, the review teams or committees specified above.

\section{Authorization of the Operation}

DOE Order 5481.1 requires that DOE Operations be authorized based on the Risk of the Operation as well as other programmatic considerations. This section establishes authorization requirements based on ES\&H considerations documented by the SAR system only. Where other programmatic considerations require higher authorization levels than those established herein, the higher authorization level shall take precedence. There will be exceptions to. the levels of authorization cited below and in Figure 4, dependent on the residual risk identified for an Operation. The PETC Director will establish guidelines on what are acceptable risks. If these guidelines are exceeded, authorization by the Deputy Director and/or Director will be required.

a. Authorization shall be a written determination that, based on the SA of the Operation and its Review, the Risk of the Operation as defined in the SA is acceptable to DOE.

b. Operations for which no SAR is required (as determined in Subsection A) shall be authorized by the CAM/PM under whose cognizance the Operation will be conducted.

c. Operations for which a Level 1 SAR is performed shall be authorized by the $\mathrm{BC} / \mathrm{PM}$ under whom the 0peration will be conducted, with the following exception: if the SA has identified any potential hazard(s) which could result in death or permanent total disability, the DM under whom the Operation will be conducted shall authorize the Operation. ES\&H Division reviewer shall identify such cases in the course of the review.

d. Operations for which a Level 2 SAR is performed shall be authorized by the responsible DM.

e. Operations for which a Level 3 SAR is performed shall be authorized by the PETC Director. 
1. DOE 5481.1 requires that significant modifications to Qperations will be authorized to signify that a determination has been made that the Risk of the modified Operation is acceptable to DOE.

2. To fulfill this requirement, all modifications to Operations shall be assessed to determine the ES\&H implications of the modification, the validity of the current $\mathrm{SA}$ if the modification is approved, and requirements for updating the SA.

3. The administrative procedure. for modifications is illustrated in Figure 5. Guidance for assigning modification levels to proposed modifications is given in Table I.

4. The CAM/PM of the Operation shall be responsible for determining the modification level in which the proposed modification to his Operation falls.

5. Assessment of ES\&H Impact(s) of Modifications

a. Minor and Moderate Modifications - The CAM/PM shall determine whether the proposed modification has any ES\&H Impact(s). ES\&H Impact is defined to be any of the following:

(1) Introduces a hazard not covered in the SA.

(2) Increases the likelihood of an identified hazard in the SA.

(3) Increases the severity of an identified hazard in the SA.

b. Major Modifications - An update of the SA is required for major modifications and shall be prepared in accord with the provisions of Section $I$, Subsections $A$ and $B$.

6. Review of Assessments/SA of Modifications

a. Minor Modification - No formal review is required. The Safety Branch may conduct audits of ES\&H Impact Assessments at its discretion.

b. Moderate Modification - The ES\&H Division shall review the CAM/PM"s assessment of impacts, determine whether a SA update should be made, and forward their recommendations to the $\mathrm{BC}$.

c. Major Modification - The updated SA shall be reviewed in accord with the provisions of Section I, Subsection C. 


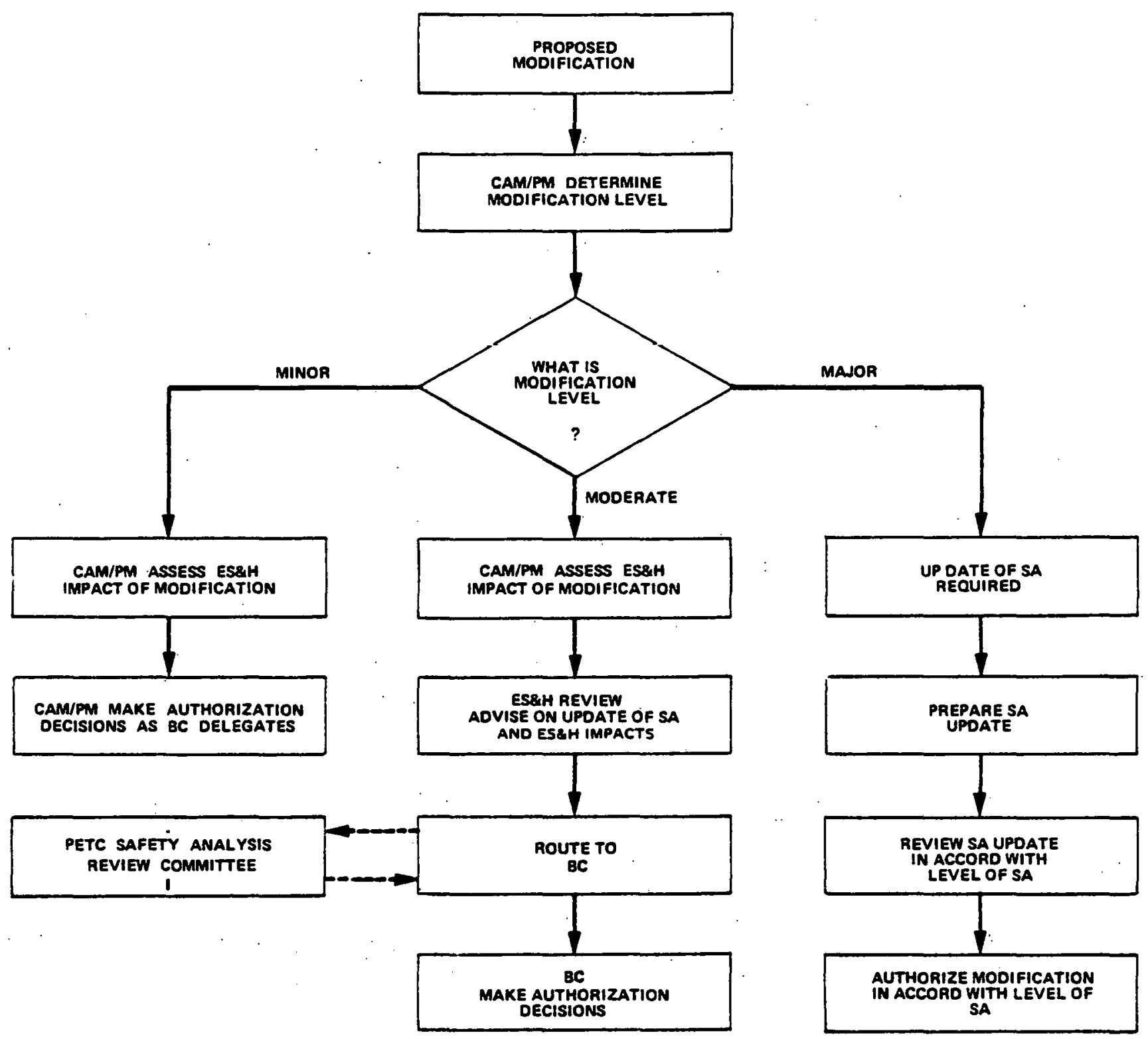

Figure 5. Modifications to the Operation 
TABLE I

GUIDELINES FOR ASSIGNING MODIFICATION LEVELS

Modification Leve1

Minor Modification

Moderate Modification

Major Modification

\section{Descriptions}

Change in operating pressure, temperature, flow rate, feed concentration/composition, catalyst (same type), or similar changes. Interchange of components; change in component material of construction; a change in

- Iine size, routing, or material of construction; or similar modifications. Minor modifications are restricted to direct replacements of an item(s) by another, usually to improve reliability or operability, which do not change the technology or process of the operation.

Changes in hardware which involve repiping, addition or replacement of equipment items which alter the process but not the basic technology; change in catalyst family; or change in the control logic or interlock system. Moderate modifications are restricted to those which are accomplished without engineering design packages or issuance of formal drawings.

Changes in hardware which involve changes in the types of unit operations, the technology involved, or major redesign. Major modifications are generally accomplished via an engineering design package involving issuance of equipment specifications and/or engineering drawings. 


\section{Authorization of Modifications}

The authorization required for a modification shall be as follows:

a. Minor Modification - responsible CAM/PM approval of the Work Order to accomplish the modification shall constitute authorization.

b. Moderate Modfication - responsible BC.

c. Major Modification - in accord with level of SA update and provisions of Section I, Subsection C.

d. Exceptions - If any modification is assessed to have ES\&H impacts which would increase the leve1 of authorization from that originally required (provisions of Subsection $C$ ), then the higher level shall take precedence.

8. Decommissioning shall be considered to be a moderate modification of the Operation.

9. Audits

a. An update of the SA for an Operation may be required after a number of modifications, none of which in and of themselves dictated an update. The ES\&H D1vision should audit Operations against the current SA, at their discretion, and recommend that the line organization provide an updated SA where ES\&H considers an updated $\mathrm{SA}$ is necessary. 


\section{E. BACKFITTING}

DOE Order 5481.1 requires that on-going operations with the potential for major on-site or off-site impacts to people or the environment be identified and be subjected to Safety Analysis and Review. To fulfill that requirement, the following administrative procedures are established:

1. Backfit SA requirements for existing Operations which are dormant (i.e., facility not being used) need not be considered until such time as use of the facility is contemplated or planned. An exception might arise if the schedule for providing the SA would adversely impact the schedule to activate the facility. In such cases, it may be desirable to provide the SA independent of facility activation.

2. Backfit SA will normally be triggered by the Work Plan/ Procurement Package for an in-house Operation or contract proposal. If an on-going Operation is not subject to the PETC Annual Control Process Program (e.g., not funded annually via a PTPA) it shall be independently subject to a SA Requirement Determination.

3. Backfit Operations shall be subject to the requirements for providing the $S A$, reviewing the SA, authorizing the Operation, and modifications (Section I, Subsections A, $B, C$, and $D)$ with the following exceptions:

a. Backfit Operations which do not have the potential for major on-site or off-site impacts to people or the environment can be excluded. If such is the case, the SA Requirement Determination for the Operation should be forwarded through the line organization to the Assistant Director with a request for exclusion. The Ässistant Director may approve of such requests at his discretion.

b. Exemptions from Backfit SA requirements may be requested. Such requests shall be routed to the Deputy Director for approval, and then to the FE : Undersecretary for authorization. 
SECTION III

SAFETY ANALYSIS TECHNICAL SPECIFICATIONS

This section presents the technical requirements and specifications for: (1) determining if an Operation requires a Safety Analysis and the level of Safety Analysis appropriate if one is required, and (2) the content for each of the three levels of Safety Analysis.

\section{A. SAFETY ANALYSIS REQUIREMENT-DETERMINATION}

1. General Requirements

a. The SA Requirement: Determination is an evaluation to determine: 1) whether or not an operation is administratively excluded from DOE 5481.1.2): whether or not it is excluded on technical grounds, if it is not administratively excluded, 3) the level of $\mathrm{SA}^{-}$which is appropriate, if the operation is neither administratively or technically excluded, and 4) the budget allocation the the SA.

b. Administrative exclusions are determined directly from a comparison of the Operation with the DOE 5481.1 criteria for administrative exclusions. Administrative exclusions are:

..."(a) Construction related activity.

(b) Nuclear safety of weapon designs.

(c) Operations for which DOE does not assume programmatic responsibility for ES\&H.

c. An Operation is excluded from DOE 5481.1 on technical grounds if the hazards of the Operation are of a type/ magnitude that are routinely encountered and/or accepted by the pubiic.

d. If a SA is required, the Determination establishes the level of SA which is appropriate and an estimated SA cost.

\section{SA Requirement Determination Checksheets}

The SA Requirement Determination consists of four checksheets or forms for determining the SA requirements for an Operation. The logic diagram which specifies the conditions under which each of the sheets is completed is shown in Figure 6. Each of the sheets is discussed individually 

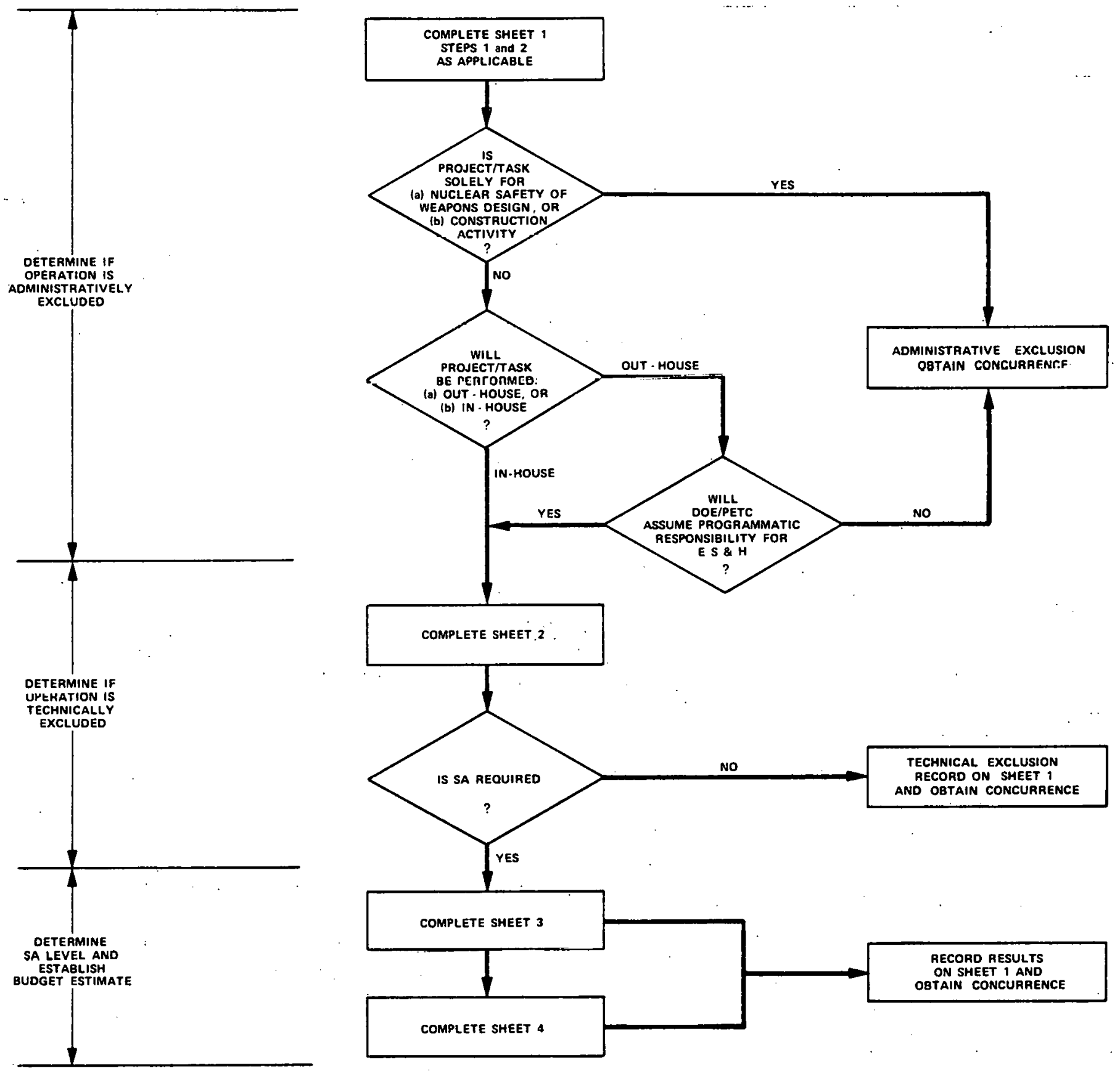

Figure 6. SA Requirement Determination Logic Diagram 
in the subparagraphs which follow. Definitions of terms used in the sheets are given in Table II (Page 27).

\section{a. Sheet 1 - Summary and Signatures}

This form is for recording administrative exclusions; and for summarizing the results of other sheets, if completed; and also contains a signature block for the preparer and for obtaining ES\&H concurrence. Sheet 1 is presented on Page 29.

b. Sheet 2 - Hazards Generally Encountered/Accepted

(1) This form is for determining whether or not an Operation is excluded from DOE 5481.1 on technical grounds, once. it has been established 1 t is not administratively excluded. The form is designed to evaluate whether the potential hazards of an Operation are of a type or magnitude routinely encountered and/or accepted by the public. Sheet 2 is presented on Page 30.

(2) Sources of material NFPA ratings are identified in the Bibliography.

(3) This form is designed for use at any stage in the life cycle of the Operation: Work Plan/Procurement Package, Design, Construction, or Backfit.

c. Sheet 3 - Level of Analysis

(1) This form is for determining the level of SA which is appropriate, once it has been determined via Sheet 2 that a $S A$ is required. Sheet 3 is presented on Page 31 .

(2) The criteria for establishing the level of SA are based on the potential consequences of incidents as determined from a consideration of type and scale of operation, materials in use, and personnel and siting factors.

(3) Terms used on the sheet are defined in Table II (Page :27).

d. Sheet 4 - Budgetary Cost Estimate

(1) This form is for establishing a budgetary cost estimate for the required SA as determined by previous sheets. Sheet 4 is presented on Page 32. 
(2) Step 1 is completed for backfit Operations or Operations which will utilize pre-existing facilities only. Information regarding the previous operating experience; existing safety analysis, safety studies, or other safety related documentation; and previous accident experience is recorded. The extent and applicability of this information is important in determining if the project can be operated before the Safety Analysis is completed. A judgment must be made in this respect.

(3) Step 2 is for establishing a budgetery cost estimate, based on the level of $\mathrm{SA}$ and one of two guideline criteria: The extent and applicability of existing analyses should be factored Into the dererminarion of a cost estimate for SA of backfit or pre-existing facilities. 


\section{A. Type of Operation}

Non-Chemical Unit

Laboratory Unit

Bench Scale Unit

Process Development Unit (PDU)

Pilot Plant

Demonstration Plant

Commercial Demonstration Plant
A unit consisting of mechanical, electrical, pneumatic, and/or hydraulic equipment; and whose function does not include the chemical analysis, processing, or oxidation of a feed material.

A very small-scale unit used in performing process analysis, a single unit operation, or for similar purposes; and typically sized such that it may be installed in a laboratory fume hood, or on a lab bench or table top.

A smal1-scale unit for testing process concepts and/or operating parameters, or for evaluating feedstocks, catalysts, or materials of construction in a process.

A system used to study the effects of process variables on performance; normally sized between a bench-scale unit and a pilot plant.

A chemical process plant containing all the process steps of a commercial unit, but on a smaller scale, for the purpose of studying the technical and economic feasibility of the integrated process and acquiring engineering data to design larger sized plants.

A near-commercial-size plant containing a single modular unit using commercial-sized components for the purpose of demonstrating the economic, environmental, and productive validity of the plant.

A full-scale commercial plant combining several modular production units for the purpose of resolving commercial investment uncertainties. 
B. Technology

State-of-the-Art

Advanced

C. Personne1 Exposure

Remote Operation

Occasionally Exposed

Frequently Exposed

Normally Exposed
Technology that is commercially available and can be purchased with some degree of performance warranty .

Technology that is not commerclally available but is in some phase of development. Generally referred to as 2nd generation if at the pilot plant stage or ready for demonstration; 3rd generation if at the bench-scale or early PDU phase of development.

Operation is designed to be conducted with operators located in a remote or protected location. No impact to personnel expected if operational incident occurs.

Operation is designed to function unattended but personnel make rounds on some regular basis to take readings or samples.

Personnel normally in the areas of the Operation but may or may not be exposed depending on exact 10cation in the event of an incident.

Personnel will be impacted by Operational incidents when at normal work station. 
SAFETY ANALYSIS REQUIREMENT DETERMINATION

SUMMARY AND SIGNATURES

OPERATION:

Sub-Operation (if any):

i. SAR not required (Check as applicable)

$\square$ Solely construction activity

Nuclear safety of weapon designs

$\square$ Contract, PETC/DOE will not assume ES\&H responsibility

If any checked, proceed to Step 6.

2. SAR may be Required (Check as applicable)

$\square$ Contract, PETC/DOE will assume ES\&H responsibility

$\square$ In-House operation

3. Complete Sheet 2 and attach

SA not required. Go to Step 6.

SA is required. Go to Step 4.

4. Complete Sheet 3 and attach.

Level. SA required

5. Complete Sheet 4 and attach Cost estimate $\$$

New operation (SAR must be complete before operation commences)

Preexisting facilities. Should SAR be completed before facility put to next use?

YES

NO

6.

Signature of preparer

Title

Date

7. $\square$ Concur $\square$ Do. not concur

Signature of reviewer

Title

Date

Reasons and Comments: 


\section{HAZARDS GENERALLY ENCOUNTERED/ACCEPTED}

OPERATION:

Sub-Operation (if any)

1. Answer the following for the operation

YES NO

- Any operating temperatures above $120^{\circ} \mathrm{F}$ or below $-20^{\circ} \mathrm{F}$ ?

- Any operating pressures above 15 psig or below ambient?

(3)

- Any equipment rotating above $4000 \mathrm{rpm}$ ?

- Any materials with NFPA Health Hazard Rating of 2 or above?

- Any materials with NFPA Flammability Rating of 2 or above?

- Any materials with NFPA Reactivity Rating of 2 or above?

- Any tools and/or equipment not typically found in the home or office?

- Any sources of ionizing radiation other than instrumentation?

- Any other factor(s) which indicate(s) a SA is needed

$\square$ All of the above checked NO. SA is not required

Some of the above checked YES. Proceed to Step 2

2. Certain DOE operations may involve equipment and/or materials which result in an answer of YES in Step 1, but which represent only hazards of a type or magnitude which are routinely encountered and/or accepted by the public. Check as applicable:

$\square$. Motor vehicle operation, maintenance

(types of vehicles used by the general public)

Kitchen and domestic appliances

Portable power tools

Machine shop equipment

Portable electric heaters

Utility boilers which meet the following conditions:

Built; instrumented, inspected, and tested to ASME Code

Capacity: $\leq 250,000 \mathrm{lb} / \mathrm{hr}$ at $\leq 250 \mathrm{psig}$

Other - Identify:
Small quantities ( $\leq 5$ gallons) of commercial fuels and lubricants used solely in operation of machinery and vehicles

Office equipment

Domestic water systems

Domestic hot water systems

3. Considering the exclusions of Step 2, are there any items in Step 1 which are still answered YES?

YES $S A$ is required

NO SA is not required

4. 


\section{SAFETY ANALYSIS REQUIREMENT DETERMINATION}

\section{LEVEL OF ANALYSIS}

OPERATION:

Sub-Operation (if any)

1. Short description:

State-of-the-Art

Advanced Technology

2. Type of operation

$\square$ Non-chemical

$\square$ Laboratory

$\square$ Bench-scale

$\square$ PDU

$\square$ Pilot plant

$\square$ Demonstration

$\square$ Commercial

5. Operating parameters:

Thruput or batch size

Operating temperature range

Operating pressure range

6. Considering the type of operation, process, materials, personnel and siting factors, assign a Level of SA based on consequences of potential incidents as follows:

Non-chemical or laboratory. unit: Level 1

Bench-scale unit:

Level 1 or 2 using criteria below

Process development unit

Level 1, 2 or 3 using criteria below

Pilot plant:

Level 2 or 3 using criteria below

Demonstration or Commercial Units
Other considerations:

Level 3

CRITERIA Level 3 - Potential for major off-site impacts

Level 2 - Potential for permanent disability or death, or significant equipment/facility loss on-site

Level 1 - Negligible potential for serious injury, and loss of equipment not a major concern

Based on the above, a Level SA is assigned. (Highest level which applies)

7. 
SAFETY ANALYSIS REQUIREMENT DETERMINATION

BUDGETARY COST ESTIMATE

OPERATION:

Sub-Operation (if any)

1. Complete this Step for backfit operations only, otherwise go to Step 2.
A: Operating experience
B. Previous Analysis
C. Accident experience
Years
None applicable
No significant accident
Use
$\square$ Qualitative
Disabling injury

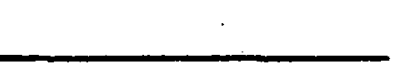
$\square$ Quantitative
$\square$ Facility damage
$1-\div---\ldots--\infty-\ldots$ Fatality

D. Considering the factors above, should the Safety Analysis be completed prior to the operation being put to next use?

$\square$ YES

$\square$ NO

2. The following Budgetary Cost Estimate Guidelines are based on a percentage of EITHER the construction cost of the operation OR the design engineering manpower cost. Use the upper end of the ranges for a complete Safety Analysis, the lower end of the ranges for a complete Process Hazards Analysis only. Better estimates can be made as SA experience is accumulated.

\begin{tabular}{ccc} 
SA Level & $\begin{array}{c}\text { Percent of Construction } \\
\text { Cost Basis }\end{array}$ & $\begin{array}{c}\text { Percent of Design } \\
\text { Engineering Basis }\end{array}$ \\
\cline { 2 - 3 } 1 & $0.1 \cdot 0.3$ & $2 \cdot 4$ \\
2 & $1 \cdot 2$ & $5 \cdot 10$ \\
3 & $2 \cdot 4$ & $5 \cdot 10$
\end{tabular}

For backfit operations consider the extent and applicability of existing analyses when determining budget allocation.

Level of SA (from Sheet 3):

Cost estimate $\%$ of $\$$ $=\$$

Basis and reasoning:

3. 


\section{B. SAFETY ANALYSIS DATA PACKAGE}

1. The SA Data Package consists of three. forms for collection of important information about the process, materials, and equipment used in the operation. Also included is information about the surroundings and potential exposure.

2. Sheet 1 (Page 34) - This form includes a brief, one paragraph description of the Operation and a summary. of the materials used in the process. Included are data on the hazardous characteristics of the materials used.

3. Sheet 2 (Pagc 35) - This form presents exposure considerations such as number of personnel present, distance to plant boundary, etc.

4. Sheet 3 (Page 36) - This form should be completed for each item of major equipment in the Operation. Examples of what is considered major equipment are presented in Table III (Page 37). 
SAFETY ANALYSIS DATA PACKAGE

PROCESS DESCRIPTION AND MATERIAL HAZARD RATINGS

OPERATION:

Sub-Operation (if any):

1. Process Description

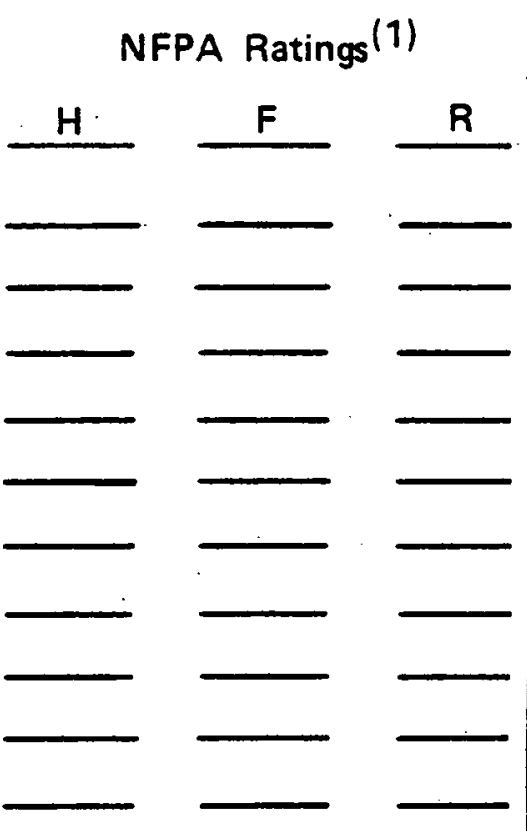

(1) H. Health Hazard

F . Flammability

R - Reactivity 
SAFETY ANALYSIS DATA PACKAGE

SITING AND PERSONNEL. FACTORS

OPERATION:

Sub-Operation (if any):

1. Siting Factors

Distance to nearest plant building/process

Distance to plant boundary

Nature of public property beyond plant boundary

(Residential, commercial, etc., include distances)

-

Process enclosed or open

If enclosed: Room volume

Ventilation

Type of construction

2. Personnel Factors

Remote operation Distance to nearest unprotected personnel

Non-remote operation

Normally present

Persons

Frequently present

Persons

Occasionally present

Persons 
SAFETY ANALYSIS. DATA PACKAGE

MAJOR EQUIPMENT AND PROCESS MATERIALS

OPERATION:

Sub-Operation (if any):

Equipment item

Batch or continuous

Size/Volume

Does unit have pressure relief?

Material of construction

Is unit inerted?

Is unit heated?

If yes, check type(s): no. \& size

Open verit(s)

Rupture disc(s)

Relief valve(s)

Is unit cooled?

Vented to atmosphere or to collection/treatment

Is unit diked, or has

spill control?

Operating temperature

Is unit a pressure vessel?

if yes:

Constructed to ASME Code?

Operating pressure

Has unit been modified?

Working volume

Inspection frequency

Hydro test frequency

Sources of ionizing radiation

List Process Materials

Material

Flow/Rate Quantity Composition, if Mixture

Any exothermic reactions?

If yes, list reaction, heat of reaction, and any gaseous products

Preparer's Name/Title/Date 
TABLE III

EXAMPLES OF MAJOR EQUIPMENT

Particulate Solids Process Equipment

Size Reduction Equipment

Classification Equipment

Bag Houses

Pneumatic Conveying Equipment

Particulate Dryers

Chemical Process Equipment

Reactors, Kilns

Distillation Columns

Evaporators, Crystallizers

Process Heaters, Boilers

Heat Exchangers

Prime Movers

Storage/Low Energy Exchange Equipment

Storage Vessels

Decanters

Liquid/Solid Filters

The above lists are not exhaustive. These are basic guidelines for use in preparing the Safety Analysis Data package. 


\section{SAFETY ANALYSIS REQUIREMENTS}

1. General Requirements

a. Safety Analysis provided under this implementation plan shall conform to the Safety Analysis and Review System for DOE Operations, DOE Order 5481.1.

b: Safety Analysis shall fulfill the following objectives:

(1) Systematically identify potential hazards.

(2) Analyze potential impacts of identifled hazards:

(3) Confirm that reasonable measures to eliminate, control or mitigate potential hasarda arc taken.

c. The objectives of the Safety Analysis shall be fulfilled by the preparation of analyses which address in appropriate detail the following topics:

(1) Description of the Operation.

(2) Conformance with applicable guides, codes, and Standards.

(3) Identification of potential hazards.

(4) Likelihood of potential hazards.

(5) Consequences of potential hazards.

(6) Design and Operating Criteria or other control measures for the elimination, or mitigation of potential hazards.

d. To the extent possible, the Safety Analysis of an Operation shall be based on the widest range in operating conditions foreseen for that Operation, or subsequent Operations utilizing the same facilities. This should minimfze the need for subsequent Safety Analysis revisions.

e. The prescribed standards of "Operational Environment, Safety, and Health Standards" (0550), as applicable to the Operation, shall be used as a basis for determining conformance to guides, codes, and standards.

f. Consequences shall be assessed and severity categories assigned in accordance with the definitions as presented in Table IV.

g. Additional requirements for other topics which the Safety Analysis shall address are given in the Paragraphs which follow. 
TABLE IV

HAZARD SEVERITY CATEGORIES

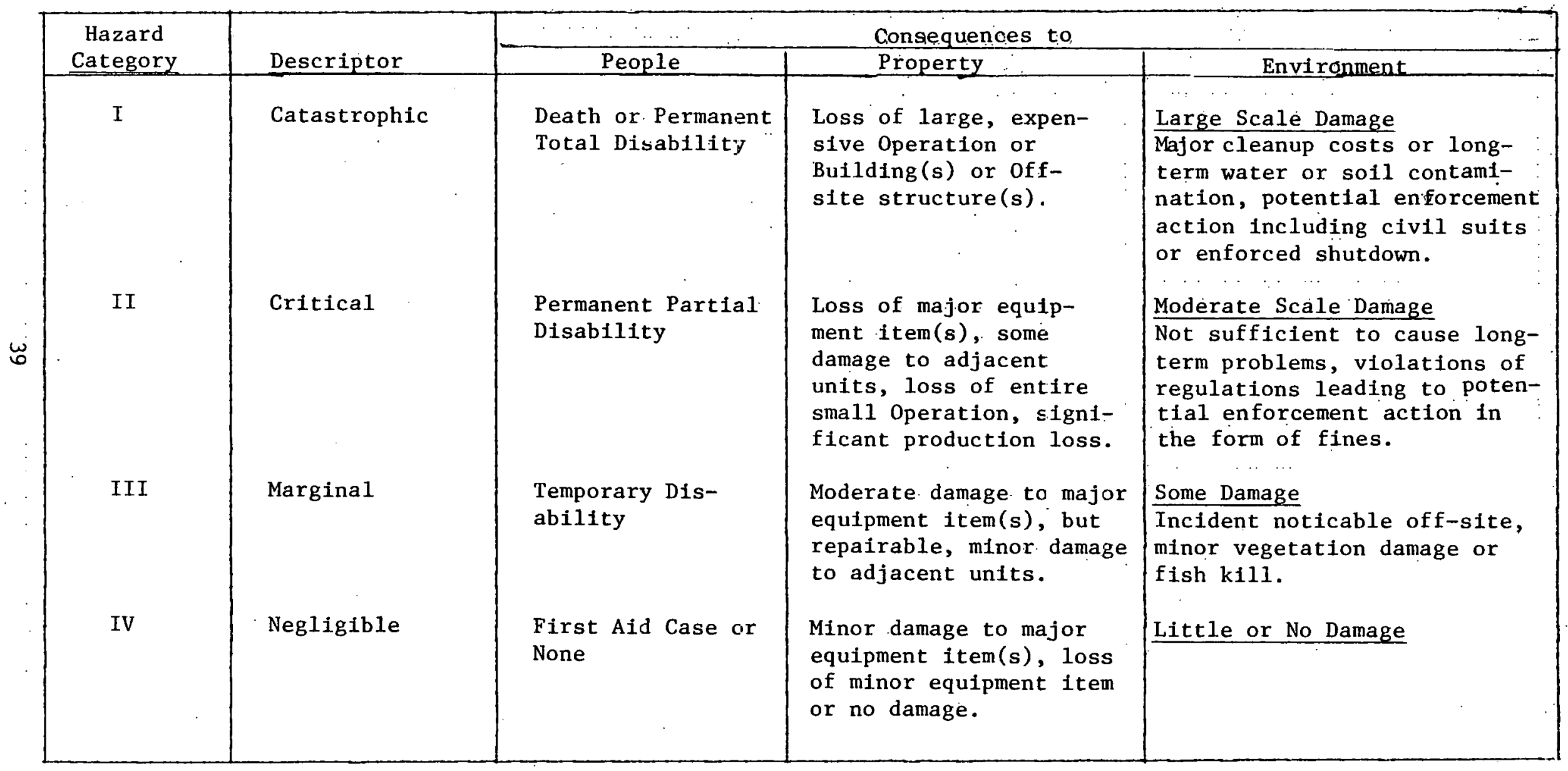




\section{2.: Organization of the Safety Analysis}

a. Operations under PETC cognizance which will require a SAR under DOE 5481.1 may represent a wide spectrum in terms of types and nature of potential hazards, source of hazards, and/or operational conditions under which they may occur. "Safety" as the term is used in Safety Analysis in accordance with DOE 5481.1 is intended to encompass all such concerns. In terms of addressing these concerns, to insure orderly, systematic, consistent, and complete analysis, a Safety Analysis is defined to consist of four distinct types of analyses: 1) Process Hazard Analysis, 2) Workplace Health Analysis, 3) Workplace Safety Analysis, and 4) Environmental Analysis.

b. "The composition of the Safety Analysis and the scope of the constituent analyses shall be as defined in Table V.

(1) Process Hazards Analysis addresses potential hazards to people, property, and/or the environment arising from fire/explosion, vessel failure, or material release as a result of component failure, operator error, or other abnormal event. Specifications for the Process Hazards Analysis are contained in Subsection D.

(2) Workplace Health Analysis addresses the potential hazard of occupational illness in conduct of the Operation at design conditions. The specifications for the Workplace. Health Analysis are contained in Subsection $\vec{E}$.

(3) Workplace Safety Analysis addresses the potential hazard of occupational injury in conduct of the Operation at design conditions. The specifications for the Workplace Safety Analysis are contained in Subsection F.

(4). Environmental Analysis addresses the potential impact to the environment from conduct of the Operation at design conditions. The specifications for the Environmental Analysis are contained in Subsection $G$.

c. : It is intended that each of the Analyses may be performed independently, or in any combination thereof: 
TABLE V

COMPOSITION OF THE SAFETY ANALYSIS

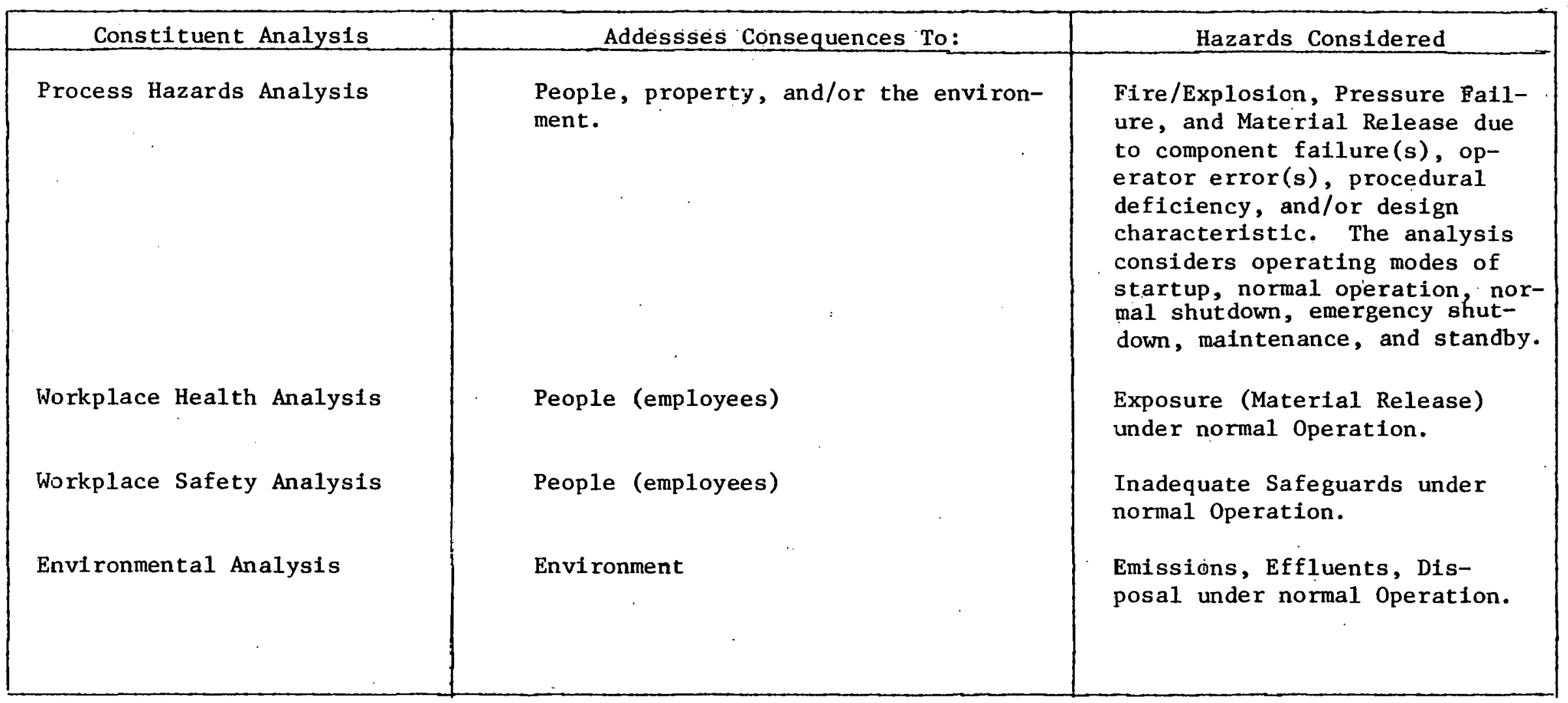


d. The Process Hazards Analysis is the "heart" of the Safety Analysis. Process hazards represent the greatest potential for serious or catastrophic.consequences. The concerns addressed by the other three constituent analyses are normally also addressed in some manner by other activities within the overall Safety function, such as Occupational Safety and Health Plans, OSHA Compliance Inspections. Environmental Impact Assessments, Environmental Impact Statements, etc. They are included within the SARS umbrella for completeness and as a means of confirming that reasonable measures to eliminate, control, or mitigate these types of hazards have been taken. For these reasons, it is expected that the greatest portion of the SA effort should be devoted to Process Hazards.

\section{Levels of Safety Analysis}

a. The scope and depth of analysis effort.required to accomplish the Safety Analysis objectives. is a function of parameters of the Operation such as scale of Operation, technology involved, properties of materials involved, complexities of the control system among others. These factors are, in turn, primarily process related and addressed by the Process Hazards Analysis.

b. To provide Safety Analysis with the flexibilitty to address the spectrum of Operations in terms of size, complexity, or hazard impact, three levels of safety Analysis are established, referred to as Level $1 \mathrm{SA}$, Level $2 \mathrm{SA}$, and Level $3 \mathrm{SA}$ respectively. The Level of the SA is in turn determined by the level of Process Hazards Analysis which is appropriate for the SA, since the Process Hazards Analysis is expected to constitute the major portion of the SA.

c. The level of SA which is appropriate is determined by the Safety Analysis Requirement Determination in accordance with Subsection A.

d. During the progress of any SA it may become evident that a different level of SA would be more appropriate. Should such be the case, a change in SA level should be sought from the individual who authorized the original SA. 


\section{PROCESS HAZARDS ANALYSIS REQUIREMENTS}

1. General Requirements

a. Process Hazards Analysis shall address potential hazards arising from component failure(s), operator error(s), process upset, procedural deficiency, or design characteristic.

b. Process Hazards Analysis shall address the operating modes of: startup, normal operation, normal shutdown, emergency shutdown, maintenance, and stand-by.

c. Process Hazards Analysis shall address consequences to people (employee and/or public), property, and the environment.

d. Process Hazards Analysis shall address the topics specified for Safety Analysis, Subsection C.

2. Information Package. General requirements for the information package which should be supplied to the individual or organization who will perform the Process Hazards Analysis, are as follows:

a. Administrative Information

(1) Bounds of the Operation

(2) Level of analysis to be performed, with specifications

(3) Risk criteria to be used as a basis for corrective recommendations:

(4) Reporting requirements and format

(5) Technical liaison/monitor

b.. Technical Information

(1) Description of the Operation

(2) Operating procedures

(3) Layout drawings

(4) Equipment specifications and drawings

(5) Design criteria 
(6) Process Flow Diagrams, Piping and Instrument Diagrams

(7) Control Logic and Interlock Diagrams

(8) Material Data

\section{Level 1 Process Hazards Analysis Specifications}

a. The Level 1 Process Hazards Analysis is a qualitative hazards analysis.

b. Description of the Operation. A functional block diagram of the Operation accompanied by a written description shall be provided.

c. Conformance to Codes and Standards. Design philosophy and specifications for equipment shall be reviewed for compatibility with safety standards deemed applicable. Deviations shall be documented. An on-site review shall be conducted to audit compatibility of equipment with stated design criteria used (Installation Phase Analysis only).

d. Identification of Potential Hazards. Potential process hazards of the Operation shall be identified in a systematic manner. This may be done by a detailed inspection and engineering analysis, or by any other formal and recognized hazards anälysis methodology. (e.g., FMEA, FTA).

e. Likelihood of Occurrence. The likelihood of occurrence of each identified hazard shall be ranked qualitatively, using the descriptions given below. Ranking should be established considering such factors as number of independent failures required, previous experience, severity of service, and magnitude of design safety factor. The qualitative likelihood rankings are:

\begin{tabular}{|c|c|}
\hline Ranking & Description \\
\hline Frequent & Likely to occur often \\
\hline Probable & $\begin{array}{l}\text { Likely to occur occas- } \\
\text { sionally }\end{array}$ \\
\hline May Occur & $\begin{array}{l}\text { Unlikely, but may occur } \\
\text { at some time }\end{array}$ \\
\hline Remote & $\begin{array}{l}\text { Unlikely to occur at any } \\
\text { time }\end{array}$ \\
\hline
\end{tabular}


f. Consequences. The consequences of each identified hazard shall be evaluated and described. A Hazard severity category, based on consequences to people, shall be assigned in accordance with the definitions in Table IV. A Hazard Severity category, based on consequences to property, shall be assigned to identified hazards with a 'Frequent' or 'Probable' likelihood.

g. Control Measures. Existing measures which control or mitigate the likelihood and/or consequences of potential hazards shall be described.

h. Recommendations. Recommendations for measures to eliminate, control, or mitigate hazards shall be made. In the absence of specific Risk Criteria, "triggers" for mandalury recommendacions shall be:

1) Category I hazards to people whose Likelihood is not 'Remote', 2) Category II hazards to people whose Likelihood is 'Probable', or 'Frequent', and 3)' Category III hazards to people whose Likelihood is 'Frequent'. In addition, any hazards with a 'Frequent' Likelihood which represent a Category I or II hazard to property, or with a 'Probable' Likelihood which represent a Category I hazard to property, shall be addressed.

i. Documentation of the Analysis. Specifications b, and c. above shall be documented in appropriate sections of the Safety Analysis Report. Specifications d. through $h$. shall be documented on Qualitative Process Hazards Analysis Sheets (illustrative example in Figure 7), accompanied by an appropriate discussion. Other report requirements and format shall be as specified by the procuring organization.

\section{Level 2 Process Hazards Analysis Specifications}

a. The Level.2 Process Hazards Analysis is a quantitative hazards analysis.

b. Description of the Operation. A functional block diagram of the Operation accompanied by a written description shall be provided. Siting of the Operation relative to other on-site Operations and off-site locations shall be evaluated. 
Date

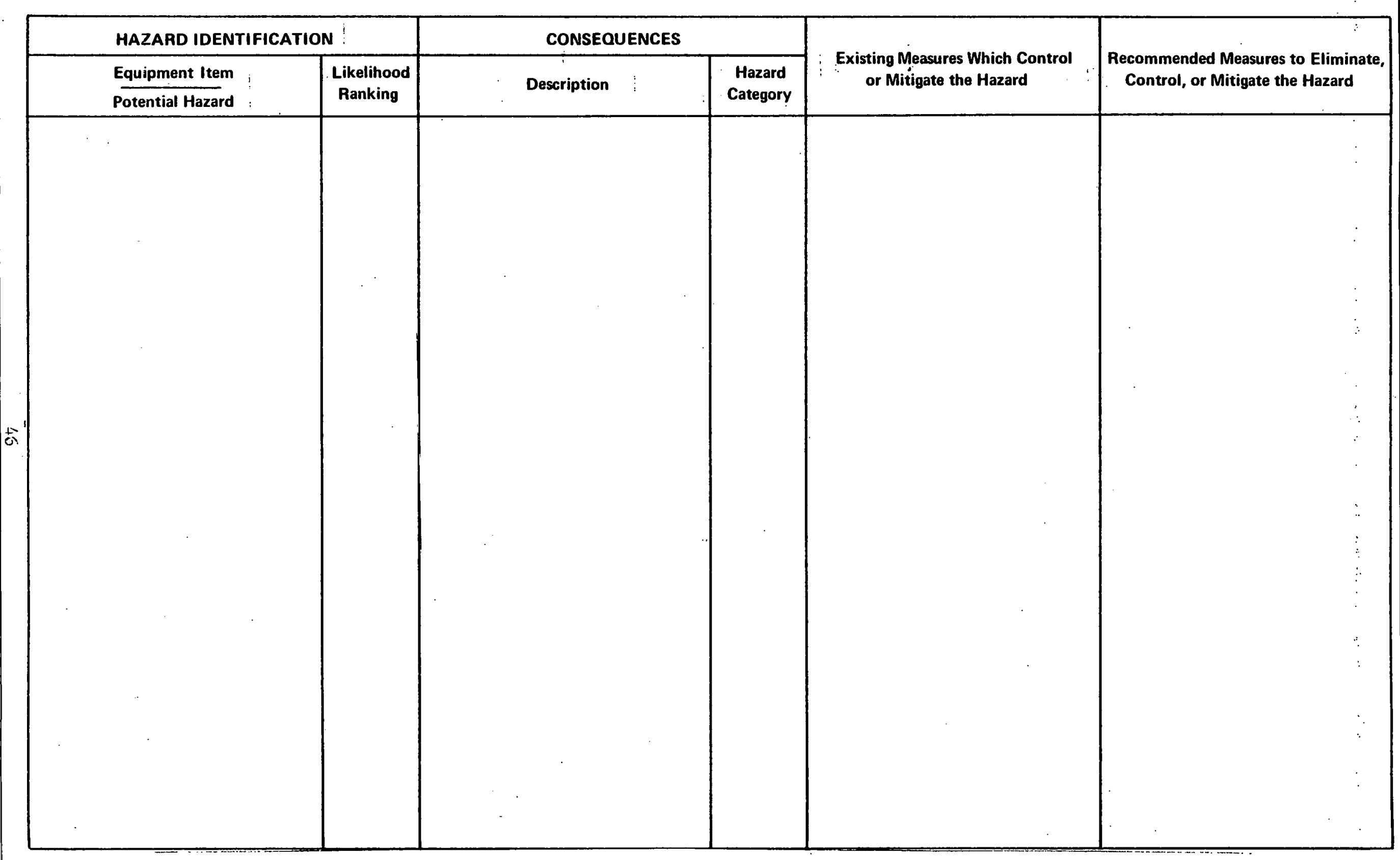

Figure 7. Qualitative Process Hazards Analysis Sheet - Illustrative Example 
c. Conformance to Codes and Standards. Design philosophy and specifications for equipment shall be reviewed for compatibility with safety standards deemed applicable. Deviations shall be documented. An on-site review shall be conducted to audit compatibility of equipment with stated design criteria used (Installation Phase Analysis: only).

d. Identification of Potential Hazards. Potential process hazards of the Operation shall be identified in a systematic manner. This may be done by detailed inspection and analysis, or by any other formal hazards analysis methodology. It is expected that the size/complexity of Operations typically requiring Level 2 SA will require some formal logic modeling to identify all credible Operation hazards. The failure logic for the hazard shall be established to the level at which failure rate data may be applied to quantify the hazard.

e. Probability of Occurrence. The probability of occurrence of each identified hazard shall be quantitatively estimated by assigning appropriate failure rate data to the factors (component failures or operator errors) in the failure logic for the hazard. To the extent possible, failure rate data should be based on actual operating experience in similar situatione. Probabilities shall be calculated on a one hour of operation basis.

f. Consequences. The consequences of each identified hazard shall be evaluated, supported by enfineering estimates or quantity-distance considerations as appropriate, and described. Hazard Severity Categories shall be assigned for consequences to people and for consequences to facilities.

g. Control Measures. Existing measures which control or mitigate the likelihood and/or consequences of potential hazards shall be described.

h. Recommendations. Recommendations for measures to.eliminate, control, or mitigate hazards which do not meet the risk criteria established. for the Operation being analyzed, shall be made. If no specific Risk Criteria are established, recommendations shall be "triggered" by the Recommendation Guidelines in Table VI.

i. Documentation of the Analysis. Specifications b. and c. above shall be documented in appropriate sections of the Safety Analysis Report. Specifications d. through h. shall be documented in an appropriate tabular form 
- TABLE VI

RECOMMENDATION GUIDELINES

Description of Risk ${ }^{(1)}$

Catastrophic Consequence to the Public or Environment

Catastrophic Consequence to Employee(s) or

Critical Consequence to the Public or Environment

Catastrophic Consequence to Facilities or

Critical Consequence to Employee(s)

Marginal Consequence to the Public, Environment, or Employee; or Critical Consequence to Facilities

Marginal or Negligible Consequence to Facilities, or Negligible Consequence to Public, Environment, or Employee
Guideline Hourly

Incident Probability

$1 \times 10^{-9}$

$1 \times 10^{-7}$

$1 \times 10^{-6}$

$1 \times 10^{-5}$

$1 \times 10^{-3}$

${ }^{(1)}$ See Table IV for guidance. 
accompanied by a full discussion. Failure rate data and the Risk Criteria used in the Analysis shall be documented. In addition, supporting Tables, Charts, Calculations, etc., as appropriate should be provided. Other report requi rements and format shall be specified by the procuring organization. Illustrations of formats for documenting the Analysis are given in Figures 8 and 9 as examples.

\section{Level 3 Process Hazards Analysis}

a. The Level 3 Process Hazards Analysis is designed to be a complete quantitative hazards analysis and risk assessment approprlate for Operations with the potential for major off-site and on-site impacts.

b. Description of the Operation. A functional block diagram of the Operation accompanied by a written description shall be provided. Siting of the Operation relative to other on-site Operations and off-site locations shall be evaluated.

c. Conformance to Codes and Standards: Design philosophy and specifications for equipment shall be reviewed for compatibility with safety standards deemed applicable. Deviations shall be documented. An onsite review shall be conducted to audit compatibility of equipment with stated design criteria used (Installation Phase Analysis only).

d. Identification of Potential Hazards. Potential process hazards of the Operation shall be identified in a systematic manner. It is expected that the size/complexity of the Operations typically requiring Level 3 SA will dictate the use of extensive logic modeling. The failure logic for the hazard shall be established to the level at which failure rate data may be applied to quantify the hazard.

e. Probability of Occurrence. The probability of occurrence of each identified hazard shall be quantitatively predicted by applying failure rate data to the failure logic for the hazard. To the extent possible, failure rates shall be based on data from actual operating experience, and shall consider materials of construction, operating service, and mode of failure of the component(s). Sensitivity analyses shall be done in cases where failure rates are unknown or suspect. Sources of all failure data shall be documented. 
f. Consequences. The consequences of each identified hazard shall be evaluated and described. A hazard severity category shall be assigned for each of the three types of consequences as follows: 1) public/environment, 2) employees, and 3) facilities. The consequence evaluation for hazards with the potential for major on-site or off-site impacts shall include quantitative evaluations based on dispersion models; meteorological data; terrain and drainage patterns; theoretical or empirical blast wave, fragment, thermal radiation models; probable ignition sources; location of off-site concentrations of people or structures, etc., as appropriate.

g. Control Measures. Existing measures wh1ch control or mitigate the likelihood and/or consequences of potential liazards shall be described and evaluated.

h. Recommendations. Recommendations for measures to eliminate, control, or mitigate hazards which do not meet the risk criteria established for the Operation being analyzed, shall be made. If no specific Risk Criteria are established, recommendations shall be "triggered" by the Guidelines in Table VI.

i. Additional Studies. Additional studies as the procuring organization deems appropriate and specifies, or as the organization conducting the SA determines appropriate, may be required in the scope of work or included optionally. Examples of such studies include the following:

(1) Specified sensitivity studies

(2) Data collection effort to develop specialized failure data bank(s)

(3) Cost-benefit studies of alternate recommendations or designs

\section{(4) Development of equipment specifications}

j. Documentation of the Analysis. Specifications b. and c. above shall be documented in appropriate sections of the Safety Analysis Report. Specifications d. through h. shall be documented in an appropriate tabular form accompanied by a full discussion. Failure rate data used and the sources shall be documented. The Risk Criteria used shall be documented. Isopleth plots of blast overpressures, flammable concentration, toxic concentration, etc., as appropriate, shall be provided. In addition, supporting Tables, Charts, Calculations, as appropriate shall be provided. Other report requirements and format shall be as specified by the procuring organization. 


$$
T
$$


HAZARDS CONSEQUENCE/SEVERITY ANALYSIS - EXAMPLE

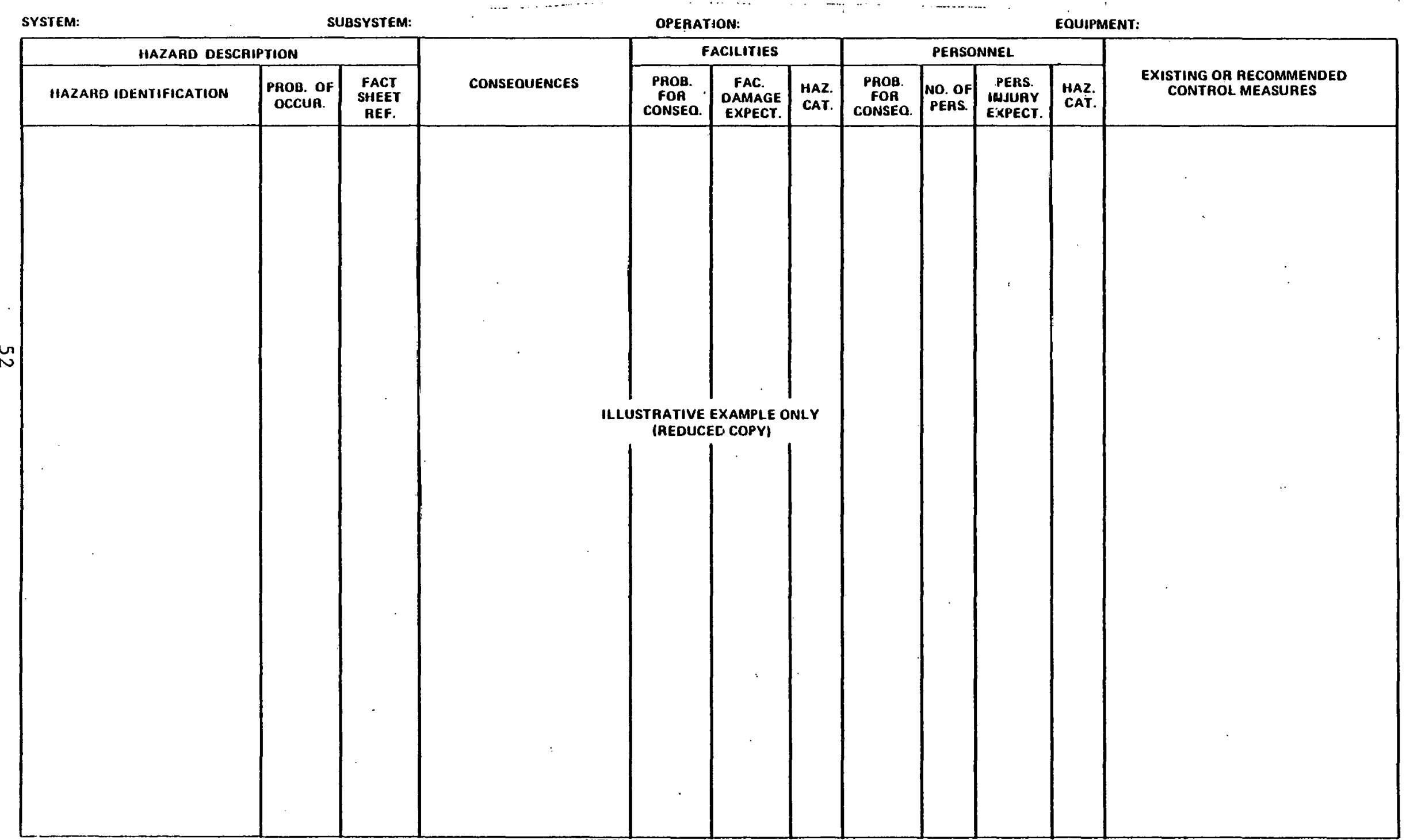

Figure 9 
E. WORKPLACE HEALTH. ANALYSTS REQUTREMENTS

\section{General Requirements}

a. The Workplace. Health Analysis shall evaluate the potent1al occupational health hazards of the Operation under normal Operation conditions.

b. The Workplace Health Analysis shall address the topics specified in Subsection C.1.C., as applicable to occupational health.

c. The Workplace Health Analysis should.be complemented by inspections and monitoring during the Operational phase of the life cycle, in accordance with the Occupational Safety and Health Plan for the facility, as applicable.

2. Information Package. Conduct of the Workplace Health Analysis requires a technical design package and all operational procedures. A physical inspection of the Operation should bc made if the analysis is done at the completion of construction or thereafter. Monitoring data should be included.

\section{Specifications}

a: Description of the Operation: A description of the Operation, with particular attention to likely sources and types of operator exposure, shall be provided.

b. Conformance to Standards. Design features, control measures, and monitoring data shall be reviewed for compatibility with prescribed Health Protection Standards (0550) deemed applicable.

c. Identification of Health Hazards: Materials involved in the Operation which represent potential oceugational health/illness hazards shall be identified and documented, The Operation, to include physical facilities and all operational procedures shall be evaluated in a systematic manner to identify credible exposures to personnel for the identified materials. 
d. Likelihood of Occurrence. The likelihood of exposure shall be qualitatively evaluated using the following rankings:

Exposure Ranking

Certain

Probable

May

Un1ikely
Definition

Exposure is normal.

Exposure not certain, but likely. Exposure may or may not occur. Exposure unlikely.

e. Consequence. The health consequences of each identified potential health hazard shall be evaluated and described.

f. Control Measures. Existing Control Measures which eliminate, control, or mitigate potential exposures shall be described and evaluated.

g. Recommendations. Recommendations for measures to eliminate, control, or mitigate exposures shall be made if exposure hazards are judged unacceptable. Recommendations for follow-up monitoring in the operational phase of the life cycle should be made, as applicable.

h. Documentation of the Analysis. Specifications $a_{\text {. }}$ and b. above shall be documented in appropriate sections of the Analysis Report. Specifications c. through g., shall be documented in an appropriate tabular fashion, such as Figure 10 accompanied by an appropriate discussion. Other report requirements and format shall be as specified by the procuring organization. 
WORKPLACE HEALTH ANALYSIS

Potential Exposure

Equipment Item or Procedural Step
Exposure

Ranking

Consequences of Exposure
Existing Contro1 Measures

Recommended Control Measurtes 


\section{F. WORKPLACE SAFETY ANALYSIS REQUIREMENTS}

1. General Requirements

a. The Workplace Safety Analysis shall address potential occupational injury hazards of the Operation under normal operational conditions.

b. The Workplace Safety Analysis shall address the toples as specified in Subsection C.1.C. as app1icable.

c. A complete Workplace Safety Analysis is possible at the completion of the construction phase of an Operation or thereafter. Prior to that the analysis may be used to influence design direction, but lack of actual physical details of the Operation as installed will preclude a comprehensive analysis.

d." The Workplace Safety Analysis should be complemented by inspections during the Operation phase of the life cycle, in accordance with the Occupational Safety and Health Plan for the facility, as applicable.

\section{Information Requirements}

a. Design Phase Analysis. At the Design Phase, an analysis will require a technical design package and design criteria for the Operation.

b. Installation Phase or Subsequent Analysis. At the completion of the installation phase or thereafter, an analysis will require a phystcal 1nspection of the operation, all operational procedures, and equipment specifications.

\section{Specifications}

a. Specifications are established to cover conduct of a Workplace Safety Analysis during the design phase or at the completion of the installation phase or thereafter. 
b. Design Phase Analysis

(1) Description of Operation. A description of the Operation with particular reference to potential occupational injury hazards shall be provided.

(2) Conformance to Standards. Design philosophy and specifications shall be reviewed for inclusion of applicable prescribed standards. Omissions shall be notepd.

(3) Identification of Hazards. The Operation shall be ieviewed to identify likely areas which will require design effort to provide adequate safeguards.

(4) Controls. Areas which may require special attention or control measures beyond normal codes and standards shall be evaluated and identified.

\section{c.. Installation Phase Analysis}

(1) Description of Operation. A description of the Operation with particular reference to potential occupational injury hazards shall be provided.

(2) Conformance to Standards. Integral to the identification of hazards.

(3) Identification of Hazards. The Operation shall be physically inspected, and all operational procedures shall be reviewed to identify equipment, situations, or procedures which appear to be unsafe or marginally safe. Types of hazards which should be considered include those presented in Table VirI.

(4) Existing Safeguards. Existing design features, control measures, or protective equipment which eliminate, control, or mitigate occupational injury hazards shall be described.

(5) Recommended Safeguards. If unsafe or marginally safe equipment, situations, or procedures are identified, recommendations for design features, control measures, or protective equipment to provide adequate safeguards shall be made.

(6) Documentation of the Analysis. The Workplace Safety Analysis shall be documented in an appropriate Analysis Report. Reporting requirenents and format shall be as specified by the procuring organization. 
TABLE VII

TYPICAL WORKPLACE SAFETY HAZARDS

A. Unsafe Structures

1. Platforms or stairs with inadequate guard rails.

2. Inadequately supported platforms, stairs, or scaffolding.

3. Ladders not conforming to standards.

B. Uņ̃afe Conditinns

1. Hot work, such as welding, without adequate precautions being taken to remove combustibles from the site and to protect the site from influx of combustibles.

2. Maintenance personnel entry of vessels with inert, flammable, or toxic atmospheres without adequate personnel protection or purging procedures.

C. Unsafe Equipment

1. Inadequate guaids un moving mechanical parts, such as gears, drive belts, motor couplings, etc.

2. Material handling equipment not suitable for the load being carried.

3. Electrical equipment not rated for the environment in which it is being used.

4. Adequate exhaust systems not provided to remove flammable or toxic dusts or vapors.

5. Hazardous personnel lifts.

6. Lines or equipment at elevated temperature without adequate insulation.

D. Inadequate Safety Equipment

1. Proper fire extinguishers not provided or inaccessible.

2. Proper automatic fire suppression equipment not provided.

3. Hazardous areas not adequately labeled or otherwise protected.

4. Personnel protect1ve equipment not readily accessible or inappropriate for the hazards involved. 
G. ENVIRONMENTAL ANALYSIS REQ̨UIREMENTS

\section{General Requirements}

a. The Environmental Analysis shall evaluate the actual or expected material release characteristics of the Operation. Consideration shall be given to emissions, effluents, and waste disposal.

b. The Environmental Analysis shall address the topics specified in Subsection C.l.c. as appliciable to environmental matters.

c: The Environmental Analysis shall be complemented by a monitoring inspection and reporting system in accordance with regulatory and emission control requirements. This system.should apply throughout the life cycle of the facility, including after shutdown, if necessary.

d. The extent of Environmental Analysis shall be determined by the scale of the Operation. The format presented here shall apply in all cases.

2. Data Requirements

a. Envi ronmental Impact Statement (EIS) (if available). A small research scale operation may not have an individual EIS.

b. Permit applications.

c. Process specifications including material balance.

d. Environmental monitoring data.

\section{Specifications}

a." Description of the Operation. A description of the Operation, with particular attention to sources of material release, control systems and waste disposal practices shall be provided.

b. Conformance to Standards. The Operation shall be reviewed and evaluated to determine if it is in conformance with the prescribed Environmental Standards (0550) and the EIS, as applicable.

c. Identification of Emission Sources. All sources of emissions, effluents, and waste materlal shall be identified, characterized and documented. 
d. Likelihood of Occurrence. This is an assessment of the material releases expected from the Operation under the normal range of operating conditions. The potential for abnormal releases of material leading to noncompliance with the applicable standards is assessed in the process hazards anaiysis.

e. Consequences. The consequences of these material releases reported in any applicable EIS should be reviewed for accuracy.

f. Control Measures. Existing or proposed control measures which eliminate, control, or mitigate release of material shall be described and evaluated.

g. Recommendations. Recommendations for measures to eliminate, control or mitigate emissions shall be made if there is evidence that the Operation will not comply with the regulations.

h. Documentation. Release sources and the controls and recommendations associated with them should be summarized in a form such as that fresented in Figure 11 . 
Emissions, Efflu-

ents, and Waste

Disposal Inventory

Source

Material

Quantity/Concentration

Contro1 Measures

Recommended Contro1 Measures 
A. SOURCE DOCUMENTS USED IN DEVELOPING THE MANAGEMENT IMPLEMENTATION PLAN

1. DOE Order 5481.1, Safety Analysis and Review System for DOE Operations, $3 / 20 / 79$.

2. DOE Order 5480.1, Environmental Protection, Safety, and Health Protection Program for DOE Operations, 5/5/80.

3. ETF Order 5480.1, Occupational Safety and Health (OSH). Manual, $8 / 13 / 79$.

4. Briefing, Safety Analysis and Review System, Office of Fossil Energy Programe, Undated.

5. Program Summary Document, FX 1981, Assistant Secretary for Fossil Energy, February 1980 (Draft).

6. DOE Manual 0550, Chapter I - Operational Environment, Safety and Health Standards.

7. PETC Annual Control Process Program Diagram.

B. SOURCE DOCUMENTS FOR HAZARD SEVERITY CATEGORIES AND RISK CRITERIA GUIDELINES

1. MIL-STD-882A, System Safety Program Requirements, 15 July 1969.

2. MPBMA OSM 385-1, System Safety Program for Modernization and Expansion Projects, U. S. Army Munitions Production Base Modemization Agency, 12 May 1980.

3. Accident Facts, 1979 Edition, National Safety Council, Chicago, IL.

4. Starr, C., 'Social Benefit Versus Technological Risk," Science, 1965, p. 1232.

C. REPRESENTATIVE SOURCES OF MATERIAL DATA AND FAILURE RATE DATA

1. Fire Protection Guide on Hazardous Materials, NFPA, latest edition.

2. Sax, N. Irving, Dangerous Properties of Industrial Materials, Fifth Edition, VanNostrand Reinhold, 19.79 .

3. The Condensed Chemical Dictionary, Ninth Edition, VanNostrand Reinhold, 1977. 


\section{BIBLIOGRAPHY (CONT'D.)}

B. 4. WASH-1400, Reactor Safety Study, Appendix III - Failure Data, U. S. Nuclear Regulatory Commission, October 1975.

5. Atallah, S., "Assessing and Managing Industrial Risks," Chemical Engineering, September 8, 1980 .

6. Sumaries of Failure Rate Data; Volume 2; Government-Industry Data Exchange Program, October 1976.

7. Lees, F. P., et al., "Some Data on the Reliability of Instruments in the Chemical Plant Environment," The Chemical Engineer, November 1971 . 
APPENDIX A

OPERATIONAL HAZARDS

DOE Order 5481.1 requires that a SAR be performed for any DOE Operation which presents hazards of a type or magnitude that are not routinely encountered and/or accepted by the public. However, no criteria or guidelines are given for establishing what types or magnitudes of hazards are generally encountered and/or accepted.

Sheet 2 of the Safety Analysis Requirement Determination establishes a set of criteria for making this judgment. In Step 1, any aspect of the environment, materials, or equipment of the Operation which could potentially be 'out-of-the-ordinary' is flagged for further study. Only if there are clearly only routinely accepted conditions, materials, and equipment is an Operation excluded from a SA by Step 1. It is recognized that the criteria of Step 1 are conservative and restrictive by necessity in order to cover all situations.

Therefore, in Step 2, some representative conditions are identified which are not excluded by Step 1, but which are considered to involve hazards routinely encountered and/or accepted by the public. Provision is made for Identifying and recording any other conditions not specifically listed. Step 2, then, consists of identifying a set of items which can be excluded from consideration as they are classified as generally encountered and/or accepted.

In Step 3, the results of Step 1 are reviewed in light of the exclusions identified in Step 2. If there are residual conditions, materials, or equipment not excluded by Step 2 then the Operation presents potential hazards of a type or magnitude not routinely encountered and/or accepted and a SA is required. 
APPENDIX B

LEVEL OF ANALYSIS

The Level of Analysis is assigned to an Operation using Sheet 3 of the Safety Analysis Requirement Determination. The prime driving force in determining the level of SA is the worst-case potential consequence of incidents in the Operation. These, in turn, can generally be related to factors. such as type and scale of Operation, materials in use, and personnel exposure and siting of the Operation.

A Level I SA is a qualitative analysis designed for Operations which are of limited size/complexity such that hazards can be adequately identified and evaluated qualitatively, or which present negligible potential for serious injury, and loss of equlpinent is not a major concern.

The Level 2 and Level 3 SA are quantitative analyses. The distinguishing feature of the Level $3 \mathrm{SA}$ is the extent and depth of the consequence analysis with regard to incidents with potential off-site impacts.

For the most part, the Level of Analysis assignment procedure requires that an assessment of potential consequences be made and the Level of Analysis be assigned accordingly using assignment criteria provided.

This approach has been taken to provide the flexibility necessary to address the various possible combinations of operational factors likely to be encountered. While this approach results in a dependency to some degree on the preparer's judgment, it is deemed preferable to a set of specific SA level assignment criteria which cannot practicably consider Operations on an individual basis. Protection against downgrading of SA concerns or improper judgment is provided by requiring that the SA Requirement Determination be reviewed and concurred-in by the Safety Branch. 
DOE Order 5481.1 specifically requires that the authorization for construction, operation, and subsequent modification of each DOE Operation be based upon an objective assessment of the adequacy of the Safety Analysis as well as other programmatic considerations. Thus, for new Operations, the SA must be prepared and reviewed prior to actual conduct of the operation.

For on-going Operations (backfit) the timing of the SAR, if required, should consider the potential residual risk represented by the Operation. Priorities should be established and SAR's performed on Backfit Operations on the basts of the priority.

It is also possible that a 'new' Operation may utilize pre-existing facilities, with or without modifications. This situation represents a 'gray' area between a strictly new and a strictly on-going Operation. This situation is treated as a backfit Operation within the framework of the Management Implementation Plan, with the requirement that the existing facility history (types and lengths of operating experience, previous analysis and/or safety studies, and accident experience) be reviewed and a judgment be made on the advisability of completing the SA prior to putting the facility to next use. Provision for recording these items is included on Sheet 4 of the Safety Analysis Requirement Determination. 


\section{APPENDIX D}

\section{BUDGETARY COST ESTTMATES}

A sufficient body of experience on the costs of SARS to enable precise.. cost estimates is presently lacking. The Office of Fossil Energy Programs undertook an effort to develop first order cost estimate guidelines and presented the guidelines in a Safety Analysis and Review System briefing (Entry A. 4 of Bibliography). These guidelines were based on contacts with a number of sources, such as A\&E firms, major oil companies, defense related activities, and professional organizations.

Sheet 4 of the Safety Analysis Requirement Determination presents guideTines for budgetary cost estimates as a function of the SA level. These guideIines are patterned after those presented in the refierenced brlefilis, with some adjustment based on the present contractor's experience with Process Hazards Analysis of defense related facilities.

SAR costs will be specific to individual Operation factors such as type of Operation and equipment and complexity of control systems. The cost estimates presented are therefore for budgetary planning purposes only.

As PETC gains SAR cost experience, better estimate guidelines can be developed.

For backfit Operations, the extent and applicability of existing analyses and studies should be constdered. 


\section{APPENDIX E}

\section{HAZARD SEVERITY CATEGORIES}

Hazard Severity Categories (Table IV) have been patterned after those presented in MIL-STD-882A. Consequences to people, property, and the environment have been. described as separate items and amplifying definitions of the scale of injury/illness or damage have been included. 


\section{APPENDIX F}

\section{RECOMMENDATION GUIDELINES}

DOE Order 5481.1 speclfies that authorlzation of an Operation signifies that a determination has been made that the risk of the Operation is acceptable to DOE. However, no criteria or guidance for establishing or determining the level of risk which is acceptable, is given. The Management Implementation Plan assigns the task of establishing acceptable risk level guidelines to the PETC Director.

For purposes of ensuring uniformity in the preparation of SA and in the development of recommendations for mitigating or controlling hazards, a set of Recommendatiuns Guldelines (Table VT, h) has been developed. The guidelines are not intended to define 'acceptable risk to DOE' or supplant guidelines to be established by the PETC Director, but are for the purpose of 'triggering' recommendations only.

The guidelines are nevertheless derived from data of the following types: 1) risk criteria used by others, 2) risk levels as represented by accident statistics, and 3) relative levels of voluntary versus involuntary risks which the general public seem to accept. Source documents are listed in Section B of the Bibliography. 


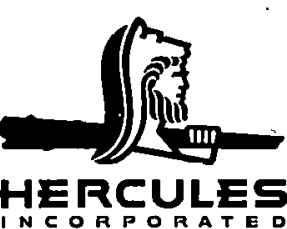

